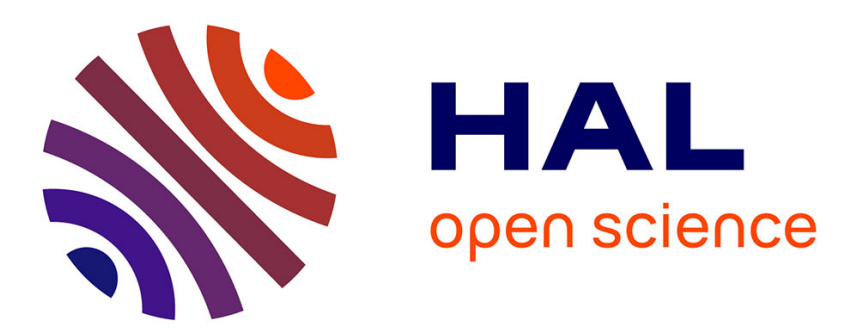

\title{
Solid-state NMR/NQR and first-principles study of two niobium halide cluster compounds.
}

\author{
Berislav Perić, Régis Gautier, Chris J. Pickard, Marko Bosiočić, Mihael S.
} Grbić, Miroslav Požek

\section{- To cite this version:}

Berislav Perić, Régis Gautier, Chris J. Pickard, Marko Bosiočić, Mihael S. Grbić, et al.. Solid-state NMR/NQR and first-principles study of two niobium halide cluster compounds.. Solid State Nuclear Magnetic Resonance, 2014, 59-60, pp.20-30. 10.1016/j.ssnmr.2014.02.001 . hal-00973433

\section{HAL Id: hal-00973433 https://hal.science/hal-00973433}

Submitted on 13 Jun 2014

HAL is a multi-disciplinary open access archive for the deposit and dissemination of scientific research documents, whether they are published or not. The documents may come from teaching and research institutions in France or abroad, or from public or private research centers.
L'archive ouverte pluridisciplinaire HAL, est destinée au dépôt et à la diffusion de documents scientifiques de niveau recherche, publiés ou non, émanant des établissements d'enseignement et de recherche français ou étrangers, des laboratoires publics ou privés. 


\title{
Solid-State NMR/NQR and First-Principles Study of Two Niobium Halide Cluster Compounds
}

\author{
Berislav Perić, ${ }^{\mathrm{a}, *}$ Régis Gautier, ${ }^{\mathrm{b}}$ Chris J. Pickard, ${ }^{\mathrm{c}}$ Marko Bosiočić, ${ }^{\mathrm{d}}$ Mihael S. Grbić, ${ }^{\mathrm{d}}$ \\ Miroslav Požek ${ }^{\mathrm{d}}$
}

${ }^{a}$ Laboratory for Solid-State and Complex Compounds Chemistry, Division of materials chemistry, Ruđer Bošković Institute, Bijenička cesta 54, 10000-HR, Zagreb, Croatia

${ }^{\mathrm{b}}$ Institut des Sciences Chimiques de Rennes, UMR 6226, CNRS - Ecole Nationale Supérieure de Chimie de Rennes, CS 50837, 35708 Rennes Cedex 7, France

${ }^{\mathrm{c}}$ Department of Physics and Astronomy, University College London, Gower Street, London, WC1E6BT, UK

${ }^{\mathrm{d}}$ Department of Physics, Faculty of Science, University of Zagreb, Bijenička cesta 32, HR10000 Zagreb, Croatia

* Corresponding author:

Address: Laboratory for Solid-State and Complex Compounds Chemistry, Division of materials chemistry, Ruđer Bošković Institute, Bijenička cesta 54, 10000-HR, Zagreb, Croatia.

Tel.: +385(1)4561178

Fax: $+385(1) 4680098$

E-mail address: Berislav.Peric@irb.hr 


\begin{abstract}
Two hexanuclear niobium halide cluster compounds with a $\left[\mathrm{Nb}_{6} \mathrm{X}_{12}\right]^{2+}(\mathrm{X}=\mathrm{Cl}, \mathrm{Br})$ diamagnetic cluster core, have been studied by a combination of experimental solid-state NMR/NQR techniques and PAW/GIPAW calculations. For niobium sites the NMR parameters were determined by using variable $B_{\mathrm{o}}$ field static broadband NMR measurements and additional NQR measurements. It was found that they possess large positive chemical shifts, contrary to majority of niobium compounds studied so far by solid-state NMR, but in accordance with chemical shifts of ${ }^{95}$ Mo nuclei in structurally related compounds containing $\left[\mathrm{Mo}_{6} \mathrm{Br}_{8}\right]^{4+}$ cluster cores. Experimentally determined $\delta_{\text {iso }}\left({ }^{93} \mathrm{Nb}\right)$ values are in the range from 2400 to $3000 \mathrm{ppm}$. A detailed analysis of geometrical relations between computed electric field gradient (EFG) and chemical shift (CS) tensors with respect to structural features of cluster units was carried out. These tensors on niobium sites are almost axially symmetric with parallel orientation of the largest EFG and the smallest CS principal axes ( $V_{z z}$ and $\left.\delta_{33}\right)$ coinciding with the molecular four-fold axis of the $\left[\mathrm{Nb}_{6} \mathrm{X}_{12}\right]^{2+}$ unit. Bridging halogen sites are characterized by large asymmetry of EFG and CS tensors, the largest EFG principal axis $\left(V_{z z}\right)$ is perpendicular to the $\mathrm{X}-\mathrm{Nb}$ bonds, while intermediate EFG principal axis $\left(V_{y y}\right)$ and the largest CS principal axis $\left(\delta_{11}\right)$ are oriented in the radial direction with respect to the centre of the cluster unit. For more symmetrical bromide compound the PAW predictions for EFG parameters are in better correspondence with the NMR/NQR measurements than in the less symmetrical chlorine compound. Theoretically predicted NMR parameters of bridging halogen sites were checked by ${ }^{79 / 81} \mathrm{Br}$ NQR and ${ }^{35} \mathrm{Cl}$ solid-state NMR measurements.
\end{abstract}




\section{Introduction}

Routine NMR studies of elements possessing large nuclear quadrupolar moments prove to be difficult due to considerable spectral broadening, sometimes impossible to overcome by MAS techniques. If these nuclei are positioned at anisotropic crystallographic sites, large quadrupolar couplings introduce dominant second and higher order broadening of central lines in the solid-state NMR spectra [1]. More and more materials containing quadrupolar nuclei are studied using static NMR spectroscopy at high magnetic fields [2,3]. This development has been followed by the increasing number of first principle calculations for the determination of NMR and NQR parameters [4-7].

Significant part of niobium halide chemistry covers compounds containing edgebridged hexanuclear clusters of niobium $\left[\mathrm{Nb}_{6} \mathrm{~L}_{12}^{\mathrm{i}} \mathrm{L}_{6}^{\mathrm{a}}\right]\left(\mathrm{L}^{\mathrm{i}}=\right.$ inner ligand, e.g. $\mathrm{Cl}, \mathrm{Br} ; \mathrm{L}^{\mathrm{a}}=$ terminal ligand, e.g. $\left.\mathrm{H}_{2} \mathrm{O}, \mathrm{OH}^{-}, \mathrm{Cl}^{-}, \mathrm{Br}^{-}\right)$. The existence of several oxidation states of $\left[\mathrm{Nb}_{6} \mathrm{~L}_{12}^{\mathrm{i}}\right]^{n+}$ cluster cores $(n=2,3,4)$ is the main characteristic of these compounds [8]. Recently, it was found that they behave as useful catalysts in various chemical reactions [9]. Nuclei of interest for NMR investigations of these compounds are ${ }^{93} \mathrm{Nb},{ }^{35 / 37} \mathrm{Cl}$, and ${ }^{79 / 81} \mathrm{Br}$. All of these nuclei are quadrupolar with high natural abundances [10].

Since the development of the Gauge-Including Projector Augmented Wave (GIPAW) method in 2001 [11], a rapid increase of its usage for calculation of solid-state NMR parameters emerged in literature $[12,13]$. As electric field gradients (EFG) at positions of resonant nuclei are determined by the overall charge distribution of crystal structure, quadrupolar interaction parameters $\left(C_{Q}\right.$ and $\left.\eta_{\mathrm{Q}}\right)$ can be obtained through any calculation method that determines the electronic ground state. Projector Augmented Wave (PAW) method can be used for such computation, even in the case of paramagnetic structures [14]. The GIPAW method provides estimation of magnetic shielding tensors $(\sigma)$ and, in recent years $J$-coupling tensors [15]. In order to extract the maximum information from solid-state NMR/NQR experiments, it is worth to combine them with PAW/GIPAW calculations to obtain EFG and CS tensors for resonant nuclei, because this approach offers direct structural interpretation of experimental solid-state NMR data.

Here we present PAW/GIPAW computations and solid-state NMR/NQR measurements of two niobium halide cluster compounds: $\left[\mathrm{Nb}_{6} \mathrm{Br}_{12}\left(\mathrm{H}_{2} \mathrm{O}\right)_{6}\right]\left[\mathrm{HgBr}_{4}\right] \cdot 12 \mathrm{H}_{2} \mathrm{O}$ (1) [16] and $\left[\mathrm{Nb}_{6} \mathrm{Cl}_{12}(\mathrm{OH})_{2}\left(\mathrm{H}_{2} \mathrm{O}\right)_{4}\right] \cdot 4 \mathrm{H}_{2} \mathrm{O}(2)$ [17], both having units with $\left[\mathrm{Nb}_{6} \mathrm{X}_{12}\right]^{2+}$ diamagnetic cluster core $(\mathrm{X}=$ halogen atom). Theoretical part of the study is oriented towards the analysis of these parameters with respect to structural features of cluster unit. In experimental determination of solid-state NMR parameters for ${ }^{93} \mathrm{Nb}$ nuclei we simultaneously fit the spectra obtained at different magnetic field values using a unique set of parameters. In addition, we performed independent NQR measurements to have a more complete picture of EFG parameters of particular sites. To the best of our knowledge, this is a first time the solidstate NMR/NQR technique is combined with the PAW/GIPAW calculations to study these unusual cluster environments for niobium and halide atoms. Additionally, this work can be considered as a continuation of the research about ability of solid-state NMR spectroscopy, combined with PAW/GIPAW computations, in the characterisation of hexanuclear halide metal clusters formed by other metals [18]. 


\section{Methods}

\subsection{Solid-state NMR measurements}

$\left[\mathrm{Nb}_{6} \mathrm{Br}_{12}\left(\mathrm{H}_{2} \mathrm{O}\right)_{6}\right]\left[\mathrm{HgBr}_{4}\right] \cdot 12 \mathrm{H}_{2} \mathrm{O}(\mathbf{1})$ and $\left[\mathrm{Nb}_{6} \mathrm{Cl}_{12}(\mathrm{OH})_{2}\left(\mathrm{H}_{2} \mathrm{O}\right)_{4}\right] \cdot 4 \mathrm{H}_{2} \mathrm{O}(\mathbf{2})$ were prepared according to procedures described in the literature [16, 17]. Purity and crystallinity of the samples were checked by additional XRD measurements. Crystalline samples were powdered and tightly packed in the NMR cylindrical glass tubes ( $\phi 4 \mathrm{~mm}$, length $10 \mathrm{~mm})$.

Static broadband ${ }^{93} \mathrm{Nb}$ NMR spectra were acquired in magnetic fields $B=6.0034 \mathrm{~T}$ and $B=12.0142 \mathrm{~T}$ (for 1), and $B=6.1952 \mathrm{~T}, B=9.0977 \mathrm{~T}$, and $B=12.0003 \mathrm{~T}$ (for 2). All acquisitions were performed by Tecmag Apollo spectrometer using static solenoid probe placed in the variable temperature insert of an Oxford Instruments wide-bore variable NMR magnet. For each set of measurements, the magnetic field was determined by measurement of ${ }^{23} \mathrm{Na} \mathrm{NMR}$ line from $1 \mathrm{M}$ solution of $\mathrm{NaCl}$ in water as a reference. Resonant frequencies of $\mathrm{KNbCl}_{6} / \mathrm{MeCN}$ and $\mathrm{NaCl} / \mathrm{D}_{2} \mathrm{O}$, as references for ${ }^{93} \mathrm{Nb}$ and ${ }^{35} \mathrm{Cl}$, respectively [10], were then calculated and all spectra are presented with respect to these references. The field stability was better than $0.1 \mathrm{ppm} /$ hour resulting with an absolute confidence interval of the measured spectra of $5 \mathrm{ppm}$. Most of the spectra were taken at $200 \mathrm{~K}$, but test measurements of central line at various temperatures between $20 \mathrm{~K}$ and $300 \mathrm{~K}$ didn't show any change in spectral shape or dramatic change in spectral width. Monotonous change of line width $(10 \%$ between $80 \mathrm{~K}$ and $300 \mathrm{~K}$ ) could be readily explained by thermal expansion. Because of large quadrupolar interactions expected for all ${ }^{93} \mathrm{Nb}$ nuclei, VOCS technique was performed [19]. Hahn echo sequence $(\pi / 2-\tau-\pi)$ was used with the duration of $\pi$ pulse $9 \mu$ s, which gives an excitation width of $67 \mathrm{kHz}$. VOCS was obtained by collecting a suitable number of Fouriertransformed Hahn echoes in frequency steps of $30 \mathrm{kHz}$. To observe the undistorted central transition $(-1 / 2 \leftrightarrow 1 / 2)$ of $\mathbf{1}$, the sweeps were done in spans from 62.09 to $63.21 \mathrm{MHz}$ (from 125.00 to $126.02 \mathrm{MHz})$ at $6.0034 \mathrm{~T}(12.0142 \mathrm{~T})$, respectively. For the central transition of $\mathbf{2}$, the frequencies were swept from 62.44 to $68.98 \mathrm{MHz}$, from 93.35 to $95.99 \mathrm{MHz}$, and from 123.50 to $130.46 \mathrm{MHz}$, for magnetic fields of $6.1952,9.0977$ and $12.0003 \mathrm{~T}$, respectively.

Static broadband ${ }^{35} \mathrm{Cl}$ NMR spectra were acquired at $T=200 \mathrm{~K}$ in magnetic field $B=$ $12.0135 \mathrm{~T}$ by using the same spectrometer and probe. Solid echo sequence $(\pi / 2-\tau-\pi / 2)$ was used with duration of $\pi / 2$ pulse $4 \mu \mathrm{s}$, which gives the excitation width of $150 \mathrm{kHz}$. VOCS was collected in frequency steps of $50 \mathrm{kHz}$, in the span from 49.00 to $51.35 \mathrm{MHz}$.

\subsection{Zero field NQR measurements}

${ }^{93} \mathrm{Nb}$ NQR measurements of $\mathbf{1}$ and $\mathbf{2}$ were done using the same laboratory equipment. All measurements on ${ }^{93} \mathrm{Nb}$ nuclei contained 1 million acquisitions and were performed with the repetition time of $5 \mathrm{~ms}$. The same acquisition parameters were used during measurements of ${ }^{81} \mathrm{Br}$ and ${ }^{79} \mathrm{Br}$ nuclei of $\mathbf{1}$. The frequency range was swept down to $8.8 \mathrm{MHz}$ which was also the lowest experimentally reachable frequency of the current study. 


\subsection{Calculations and representation of the EFG and shielding parameters}

Crystallographic data for both compounds 1 and $\mathbf{2}$ were taken from ICSD database [20] (collection codes: 50174 for $\mathbf{1}$ and 80207 for 2) where both structures are deposited without hydrogen atoms. Specific details about hydrogen atom positioning will be discussed in the part "Structures and details of geometry optimization". Atomic position optimized structures were calculated within DFT-pseudopotential plane wave method by using the CASTEP program [21]. The unit cell parameters were fixed and the cut-off energy of the plane-waves was set to $620 \mathrm{eV}$. Exchange/correlation energy was calculated within the non-local PBE functional approximation [22], with the density mixing scheme proposed by Pulay [23]. Density of the $k$-points in the reciprocal space was also kept equal for both compounds $(0.05$ $\AA^{-1}$ ), which generated $2 \times 2 \times 2$ grid for 1 and $3 \times 3 \times 3$ grid for 2 by using the Monkhorst-Pack generation scheme [24]. Ultrasoft pseudopotentials were generated using on-the-fly (OTF_USPP) generator included in the CASTEP program. Following orbitals were treated as valence: $2 \mathrm{~s}$ and $2 \mathrm{p}$ for oxygen atoms, $3 \mathrm{~s}$ and $3 \mathrm{p}$ for chlorine atoms, $4 \mathrm{~s}$ and $4 \mathrm{p}$ for bromine atoms, $4 \mathrm{~s}, 4 \mathrm{p}, 5 \mathrm{~s}$ and $4 \mathrm{~d}$ for niobium atoms and $5 \mathrm{~d}$ and $6 \mathrm{~s}$ for mercury atoms. Core electrons are treated in the scalar relativistic manner. Geometry convergence criteria were: $0.2 \cdot 10^{-4}$ $\mathrm{eV} /$ atom for total energy, $0.5 \cdot 10^{-1} \mathrm{eV} / \AA$ for maximum ionic force, $0.1 \cdot 10^{2} \AA$ for maximum ionic displacement and $0.1 \mathrm{GPa}$ for maximum stress component. Atomic positions of optimized structures can be found in Table S1 of supplementary material. Magnetic shielding tensors $(\boldsymbol{\sigma})$ and EFG tensors were calculated from optimized structures by using the NMRCASTEP code $[25,26]$. Pseudopotentials used in the NMR-CASTEP calculations were identical to those used in the optimization calculations, as well as density for $k$-point sampling $\left(0.05 \AA^{-1}\right)$, because preliminary calculations with $0.1 \AA^{-1} k$-point density showed no significant change in the calculated NMR parameters. Due to the large number of atoms in the unit cell of $\mathbf{1}$ and increased computational requirements for GIPAW calculation, the cut-off energy for plane-waves was set to $500 \mathrm{eV}$ in calculation for $\mathbf{1}$, while the value of $620 \mathrm{eV}$ was retained in the GIPAW calculation for $\mathbf{2}$. Convergence of the computed NMR parameters with respect to the cut-off energy has been checked.

Theoretically predictable magnetic shielding tensor $(\boldsymbol{\sigma})$ and experimentally determinable chemical shift tensor ( $\boldsymbol{\delta}$ or CS) are two quantities related by following relation [27]:

$$
\boldsymbol{\delta}=\frac{\sigma_{r e f}-\sigma^{s y m}}{1-\sigma_{r e f}}
$$

where $\sigma^{\text {sym }}$ represent a symmetric part of total $\sigma$ tensor and $\sigma_{\text {ref }}$ is absolute isotropic shielding of the reference compound. The eigenvalues and eigenvectors (principal axes) of $\sigma^{\text {sym }}$ tensor $\left(\sigma_{11}, \sigma_{22}\right.$ and $\left.\sigma_{33}\right)$ are quantities which are directly computed by the NMR-CASTEP (GIPAW) calculation. In this work, they are indexed according to the standard convention: $\sigma_{11} \leq \sigma_{22} \leq$ $\sigma_{33}$. Antisymmetric part of the total $\sigma$ tensor $\left(\sigma^{\text {antisym }}\right)$ does not contribute to the experimental chemical shift (shift of the frequency), but contributes to the second order response of the system, i.e. to the relaxation of the spin magnetization [28]. Euler angles $(\alpha, \beta$ and $\gamma)$, that define mutual orientation of EFG and CS tensors are computed from the calculated principal axes of the EFG and $\sigma^{\text {sym }}$ tensors, where we took into account the fact that CS and $\sigma^{\text {sym }}$ tensors 
have identical orientations [Eq. (1)]. The convention used for Euler angles follows the one from simulation program Wsolids [29] and program EFGShield [30], i.e.: the $\alpha$ angle describe rotation of the CS tensor around the $\delta_{33}$ principal axis (or around $V_{z z}$ principal axis in the initial orientation), $\beta$ angle describe rotation of the CS tensor about new direction of the $\delta_{22}$ principal axis and $\gamma$ angle describe rotation of the CS tensor about final direction of the $\delta_{33}$ principal axis. All rotations are counter clockwise, principal axes of EFG tensor are not moving and initial orientation is the one in which the principal axes $\delta_{11}, \delta_{22}$ and $\delta_{33}$ coincide with the principal axes $V_{x x}, V_{y y}$ and $V_{z z}$, respectively. From the above mentioned convention for eigenvalues of the $\sigma^{\text {sym }}$ tensor follows a following convention for the CS tensor eigenvalues: $\delta_{11} \geq \delta_{22} \geq \delta_{33}$. $V_{x x}, V_{y y}$ and $V_{z z}$ denote eigenvalues of the EFG tensor indexed by convention $\left|V_{x x}\right| \leq\left|V_{y y}\right| \leq\left|V_{z z}\right|$. Two auxiliary tensors (EFG' and $\boldsymbol{\sigma}^{\text {sym }}$ ') are also computed for the sites of interest in the structure $(\mathrm{Nb}, \mathrm{Br}, \mathrm{Cl})$. These tensors have equal eigenvectors (principal axes) as original EFG and $\sigma^{\text {sym }}$ tensors, but having all eigenvalues positive and equal in magnitude with corresponding eigenvalues of the original EFG and $\boldsymbol{\sigma}^{\text {sym }}$ tensors. Calculating the components of these tensors in the crystallographic coordinate systems (using fractional coordinates) and storing them instead of components of the atomic displacement parameters in the structure's Crystallographic Information File ("cif" file) for sites of interest, the ellipsoid representation of the EFG and $\sigma^{\text {sym }}$ tensors are obtained. For drawing such ellipsoids in this work, the program ORTEP-III was used [31].

\subsection{Simulations of the static-powder NMR spectra}

Powder solid-state NMR spectra were simulated by WSolids [29] package capable to handle convoluted quadrupolar interaction/chemical shift interactions by using a second-order perturbation theory for quadrupolar interaction with respect to Zeeman interaction. This package uses the above-mentioned parameters $\delta_{11}, \delta_{22}, \delta_{33}, \alpha, \beta$ and $\gamma$ as well as quadrupolar coupling constant $\left(C_{\mathrm{Q}}\right)$ and quadrupolar asymmetry parameter $\left(\eta_{\mathrm{Q}}\right)$ defined by:

$$
C_{\mathrm{Q}}=e^{2} q Q / h=e Q V_{\mathrm{zz}} / h
$$

and

$$
\eta_{\mathrm{Q}}=\left(V_{\mathrm{xx}}-V_{\mathrm{yy}}\right) / V_{\mathrm{zz}}, \quad\left(1 \geq \eta_{\mathrm{Q}} \geq 0\right)
$$

where $e$ is elementary charge, $Q$ is quadrupolar moment of the nucleus and $h$ is Planck constant. For ${ }^{2} \mathrm{H},{ }^{17} \mathrm{O},{ }^{35} \mathrm{Cl},{ }^{81} \mathrm{Br},{ }^{93} \mathrm{Nb}$, and ${ }^{201} \mathrm{Hg}$ nuclei, the $Q$ values of $0.0029,-0.0256$, $0.0817,0.2760,-0.32$ and 0.3850 Barn were used in calculations, respectively $\left(1 \mathrm{Barn}=10^{-28}\right.$ $\mathrm{m}^{2}$ ), as implemented in the CASTEP-NMR code [25, 26]. Alternatively to the standard representation for $\delta_{11}, \delta_{22}, \delta_{33}$, isotropic chemical shift $\left(\delta_{i s o}\right)$, chemical shift anisotropy $\left(\delta_{\text {aniso }}\right)$, and chemical shift asymmetry $\left(\eta_{\delta}\right)$ in Haeberlen notation are often used:

$$
\begin{aligned}
& \delta_{i s o}=\left(\delta_{x x}+\delta_{y y}+\delta_{z z}\right) / 3 \\
& \delta_{\text {aniso }}=\delta_{z z}-\left(\delta_{x x}+\delta_{y y}\right) / 2=3 / 2\left(\delta_{z z}-\delta_{\text {iso }}\right), \\
& \eta_{\delta}=\left(\delta_{y y}-\delta_{x x}\right) /\left(\delta_{z z}-\delta_{i s o}\right), \quad\left(1 \geq \eta_{\delta} \geq 0\right),
\end{aligned}
$$


where indexes are defined by convention $\left|\delta_{z z}-\delta_{i s o}\right| \geq\left|\delta_{\mathrm{xx}}-\delta_{i s o}\right| \geq\left|\delta_{\mathrm{yy}}-\delta_{i s o}\right|$. Wsolids also uses GB (Gaussian) and LB (Lorentzian) parameters describing broadening of the simulated lineshapes as well as a mixing parameter which represent the ratio of two types of broadening. In this work, $10 \mathrm{kHz}$ for the GB and LB parameters and 50\% for the mixing parameter in all simulations are used.

\subsection{NQR data processing}

NQR line shapes are Lorentzian line shapes, where frequencies of their centres indicate transitions between energy levels of nuclei determined completely by quadrupolar interaction. These energy levels are determined by the quadrupolar coupling constant $C_{\mathrm{Q}}$ and the asymmetry parameter $\eta_{\mathrm{Q}}$. Broadband static solid-state NMR measurements and PAW calculations showed that $\eta_{\mathrm{Q}}$ parameter for ${ }^{93} \mathrm{Nb}$ nuclei $(I=9 / 2)$ in both samples are always smaller than 0.3 , so perturbation expansion for frequencies:

$$
\begin{aligned}
& v_{1}=v( \pm 1 / 2 \leftrightarrow \pm 3 / 2)=\left(C_{\mathrm{Q}} / 24\right)\left(1+9.0333 \eta_{\mathrm{Q}}{ }^{2}-45.691 \eta_{\mathrm{Q}}{ }^{4}+\ldots\right) \\
& v_{2}=v( \pm 3 / 2 \leftrightarrow \pm 5 / 2)=\left(2 C_{\mathrm{Q}} / 24\right)\left(1-1.3381 \eta_{\mathrm{Q}}{ }^{2}+11.722 \eta_{\mathrm{Q}}{ }^{4}+\ldots\right) \\
& v_{3}=v( \pm 5 / 2 \leftrightarrow \pm 7 / 2)=\left(3 C_{\mathrm{Q}} / 24\right)\left(1-0.1875 \eta_{\mathrm{Q}}{ }^{2}-0.1233 \eta_{\mathrm{Q}}{ }^{4}+\ldots\right) \\
& v_{4}=v( \pm 7 / 2 \leftrightarrow \pm 9 / 2)=\left(4 C_{\mathrm{Q}} / 24\right)\left(1-0.0809 \eta_{\mathrm{Q}}{ }^{2}-0.0043 \eta_{\mathrm{Q}}{ }^{4}+\ldots\right)
\end{aligned}
$$

is assumed to be valid [32]. Nuclei ${ }^{81} \mathrm{Br}$ and ${ }^{79} \mathrm{Br}$ are quadrupolar with $I=3 / 2$ and only one transition frequency is possible for such nuclei: [32]

$$
v=v( \pm 1 / 2 \leftrightarrow \pm 3 / 2)=\left(C_{\mathrm{Q}} / 2\right)\left(1+\eta_{\mathrm{Q}}^{2} / 3\right)^{1 / 2}
$$

Eq. (11) is valid for all values of parameter $\eta_{\mathrm{Q}}\left(0<\eta_{\mathrm{Q}}<1\right)$. However, only one frequency is not enough for determination of both parameters $C_{\mathrm{Q}}$ and $\eta_{\mathrm{Q}}$ solely from ${ }^{81} \mathrm{Br}$ or ${ }^{79} \mathrm{Br} \mathrm{NQR}$ experiment, but the value for frequency predicted from the PAW calculations of $C_{\mathrm{Q}}$ and $\eta_{\mathrm{Q}}$ can be compared with the observed ones.

\section{Structures and details of geometry optimization}

\section{1. $\left[\mathrm{Nb}_{6} \mathrm{Br}_{12}\left(\mathrm{H}_{2} \mathrm{O}\right)_{6}\right]\left[\mathrm{HgBr}_{4}\right] \cdot 12 \mathrm{H}_{2} \mathrm{O}(\mathbf{1})$}

Structure of 1 consists of hexanuclear $\left[\mathrm{Nb}_{6} \mathrm{Br}_{12}\left(\mathrm{H}_{2} \mathrm{O}\right)_{6}\right]^{2+}$ cations (cluster units), $\left[\mathrm{HgBr}_{4}\right]^{2-}$ anions and crystal water molecules. Cluster units are based on diamagnetic $\left[\mathrm{Nb}_{6} \mathrm{Br}_{12}\right]^{2+}$ cluster cores. The structure was solved by the single-crystal X-ray diffraction method in the $F d \overline{3} m$ space group without determination of hydrogen atom positions [16]. Basic structural motif consists of two interpenetrated diamond lattices (one formed by cluster units and the other by $\left[\mathrm{HgBr}_{4}\right]^{2-}$ anions), already described in similar iso(homo)structural niobium or tantalum halide cluster compounds [33]. Due to high cubic symmetry, there is only one inequivalent niobium site, two inequivalent bromine sites (one on bridging position of the cluster unit and one from the $\mathrm{HgBr}_{4}$ anion) and two inequivalent oxygen sites (one from 
the water molecule coordinated on the cluster unit and one from the crystal-water molecule). In order to optimize the atomic (site) positions and to calculate the EFG and CS tensors for these sites, hydrogen atom positions have to be determined. This task was not straightforward because the $F d \overline{3} m$ space group possesses many symmetry operations which generate too many symmetry equivalent hydrogen atoms in the structure. This problem, characteristic for this structural type of cluster compounds, was already pointed out and analysed by Hirsch [34] who gave a prescription for the hydrogen atom positioning in the hydrated crystal structures in general. We followed his prescription, which consists of manual positioning of hydrogen atoms on sites suitable for saturation of hydrogen bonds followed by the geometry optimization using DFT pseudopotential plane wave method. Between two available sites for hydrogen atoms of crystal-water molecule, which should satisfy $\mathrm{O}-\mathrm{H} \cdots \mathrm{O}$ hydrogen bonds (Fig. 1), only one has to be chosen (H22 or H22 ${ }^{\text {iv }}$, Fig. 1). If both of these positions are occupied, then the energetically unfavourable close contacts with other hydrogen atoms upcoming from the nearby symmetry related water molecules will appear.

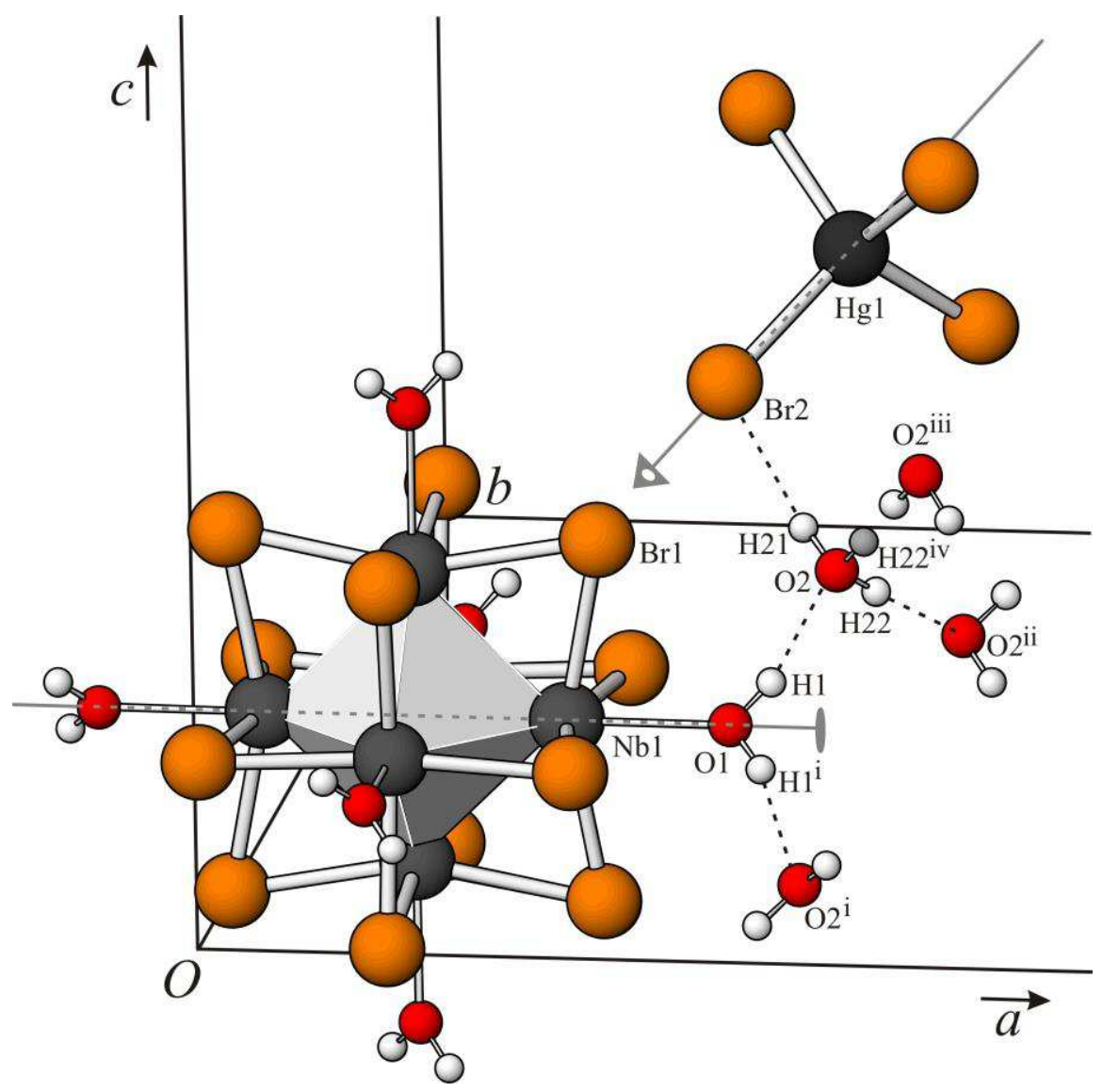

Fig. 1. Structure of $\left[\mathrm{Nb}_{6} \mathrm{Br}_{12}\left(\mathrm{H}_{2} \mathrm{O}\right)_{6}\right]\left[\mathrm{HgBr}_{4}\right] \cdot 12 \mathrm{H}_{2} \mathrm{O}(\mathbf{1})$ in the $F d \overline{3}$ space group with hydrogenbonding scheme used in the geometry optimization. Small grey sphere denote the other possible site of $\mathrm{H} 22$ atom (labelled as $\mathrm{H} 22^{\mathrm{iv}}$ ) which is not occupied. Crystallographic two-fold axis passing through $\mathrm{Nb}$ and $\mathrm{O} 1$ atoms and three-fold inversion axis passing through $\mathrm{Br} 2$ and $\mathrm{Hg}$ atoms are also shown. Symmetry codes: (i) $x, 1 / 4-y, 1 / 4-z$; (ii) $1 / 4+y, 1 / 2-z,-1 / 4+x$; (iii) $1 / 4+z,-1 / 4+x, 1 / 2-y$; (iv) $x, z, y$. 
Positions $\mathrm{H} 22$ and $\mathrm{H} 22^{\text {iv }}$ are connected by the mirror symmetry of the $F d \overline{3} m$ space group. Therefore, this mirror symmetry has to be removed to stop proliferation of symmetry related hydrogen atoms in the structure. Second hydrogen atom belonging to this crystal water molecule (H21, Fig. 1) probably points towards a third possible hydrogen-bond acceptor in vicinity, i.e. to the bromine atom from the nearby $\left[\mathrm{HgBr}_{4}\right]^{2-}$ anion (Fig. 1). Correct subgroup of the $F d \overline{3} m$ space group lacking the mentioned mirror symmetry is the $F d \overline{3}$ symmetry group [35] and in this space group the geometry optimization was successfully performed. Due to large number of atoms in conventional cubic unit cell $\left(a=b=c=21.0072 \AA, \alpha=\beta=\gamma=90^{\circ}\right)$, optimization of atomic positions was performed in the primitive unit cell ( $a=b=c=14.8543$ $\AA, \alpha=\beta=\gamma=60^{\circ}$ ), with all symmetry operations of the $F d \overline{3}$ space group taken into account. Optimized fractional coordinates of all atoms are listed in Table S1 of supplementary material. Number of inequivalent non-hydrogen atom sites has not been changed with respect to more symmetrical $F d \overline{3} m$ space group. Niobium site Nb1 lies on crystallographic two-fold rotation axis, while bridging bromine site $\mathrm{Br} 1$ is located on the general crystallographic position [i.e. on $96 \mathrm{~g}$ Wyckoff positions of the $F d \overline{3}$ space group (origin choice 2)]. Nevertheless, it lies on the missing crystallographic plane of the $F d \overline{3} m$ space group [96g Wyckoff positions of the $F d \overline{3} m$ space group (origin choice 2)] and on molecular two fold rotation axis of the $\left[\mathrm{Nb}_{6} \mathrm{X}_{12}\right]^{2+}$ cluster core. Bromine site $\mathrm{Br} 2$ from $\left[\mathrm{HgBr}_{4}\right]^{2-}$ anion is located on the three-fold inversion axis [32e Wyckoff positions of the $F d \overline{3}$ space group (origin choice 2)]. Centres of cluster units and $\mathrm{Hg}$ atoms from $\left[\mathrm{HgBr}_{4}\right]^{2-}$ anions are located on the highsymmetry tetrahedral sites [8a and $8 \mathrm{~b}$ Wyckoff positions of the $F d \overline{3}$ space group (origin choice 2)]. DFT optimized distances in metal cluster (Table S2 in supplementary material) very well agree with $\mathrm{X}$-ray data, all discrepancies are less than $0.014 \AA$. These distances are typical for the $\left[\mathrm{Nb}_{6} \mathrm{Br}_{12}\right]^{2+}$ cluster core.

\section{2. $\left[\mathrm{Nb}_{6} \mathrm{Cl}_{12}(\mathrm{OH})_{2}\left(\mathrm{H}_{2} \mathrm{O}\right)_{4}\right] \cdot 4 \mathrm{H}_{2} \mathrm{O}(2)$}

Crystal structure of 2 consists of hexanuclear $\left[\mathrm{Nb}_{6} \mathrm{Cl}_{12}\left(\mathrm{H}_{2} \mathrm{O}\right)_{4}(\mathrm{OH})_{2}\right]$ neutral cluster units, and two symmetry independent crystal water molecules. Cluster units are based on the $\left[\mathrm{Nb}_{6} \mathrm{Cl}_{12}\right]^{2+}$ cluster core which has the same oxidation state as the $\left[\mathrm{Nb}_{6} \mathrm{Br}_{12}\right]^{2+}$ cluster core in 1. Because the $\left[\mathrm{Nb}_{6} \mathrm{Cl}_{12}\right]^{2+}$ cluster core bonds two negatively charged hydroxyl anions on terminal ligand positions, the whole cluster unit is electrically neutral. The structure was solved by the single-crystal X-ray diffraction method in the low-symmetry space group $P \overline{1}$ [17] where only centres of symmetry exist in the several crystallographic sites. One centre of symmetry is located in the centre of cluster unit. Units are packed in the general triclinic crystallographic lattice with different distances between neighbouring units aligned along any of crystallographic axes. Crystal water molecules are located on the general crystallographic positions between cluster units (i.e. on $2 \mathrm{i}$ Wyckoff positions of the space group $P \overline{1}$ ) and they connect cluster units by complicated hydrogen bonding network. We used a literaturesuggested scheme for this hydrogen bonding network (Table 6 in ref. [17]). The only atom that was not determined in this scheme was the hydrogen atom from the hydroxyl group coordinated on the $\mathrm{Nb} 1$ atom (H3 in Fig. 2). Because hydroxyl oxygen $\mathrm{O} 3$ is already acceptor for two hydrogen atoms from the nearby crystal water molecules, the only possible orientation 
for $\mathrm{H} 3$ atom is towards the $\mathrm{Cl}^{\text {vi }}$ atom from the neighbouring cluster unit, the one which is translated along the $a$ axis by one period (Fig. 2). After including this hydrogen atom in the structure, positions of all atoms were successfully optimized by using the DFT pseudopotential plane wave method. Optimized coordinates are listed in Table S1 of supplementary material. In this structure, there are three inequivalent niobium sites $(\mathrm{Nb} 1, \mathrm{Nb} 2$ and $\mathrm{Nb} 3$ ) and six inequivalent chlorine sites (Cl1, Cl2, Cl3, Cl4, Cl5 and Cl6). All these atoms are located on the general crystallographic positions of space group $P \overline{1}$ (i. e. on $2 \mathrm{i}$ Wyckoff positions). Again, DFT optimized distances in metal cluster very well agree with Xray data. They are listed in Table S2 of supplementary material, and correspond to typical distances for the $\left[\mathrm{Nb}_{6} \mathrm{Cl}_{12}\right]^{2+}$ cluster unit. Discrepancies between DFT optimized and X-ray determined distances are always less than $0.01 \AA$; somewhat larger differences are observed only for $\mathrm{Nb}-\mathrm{O}$ bonds.

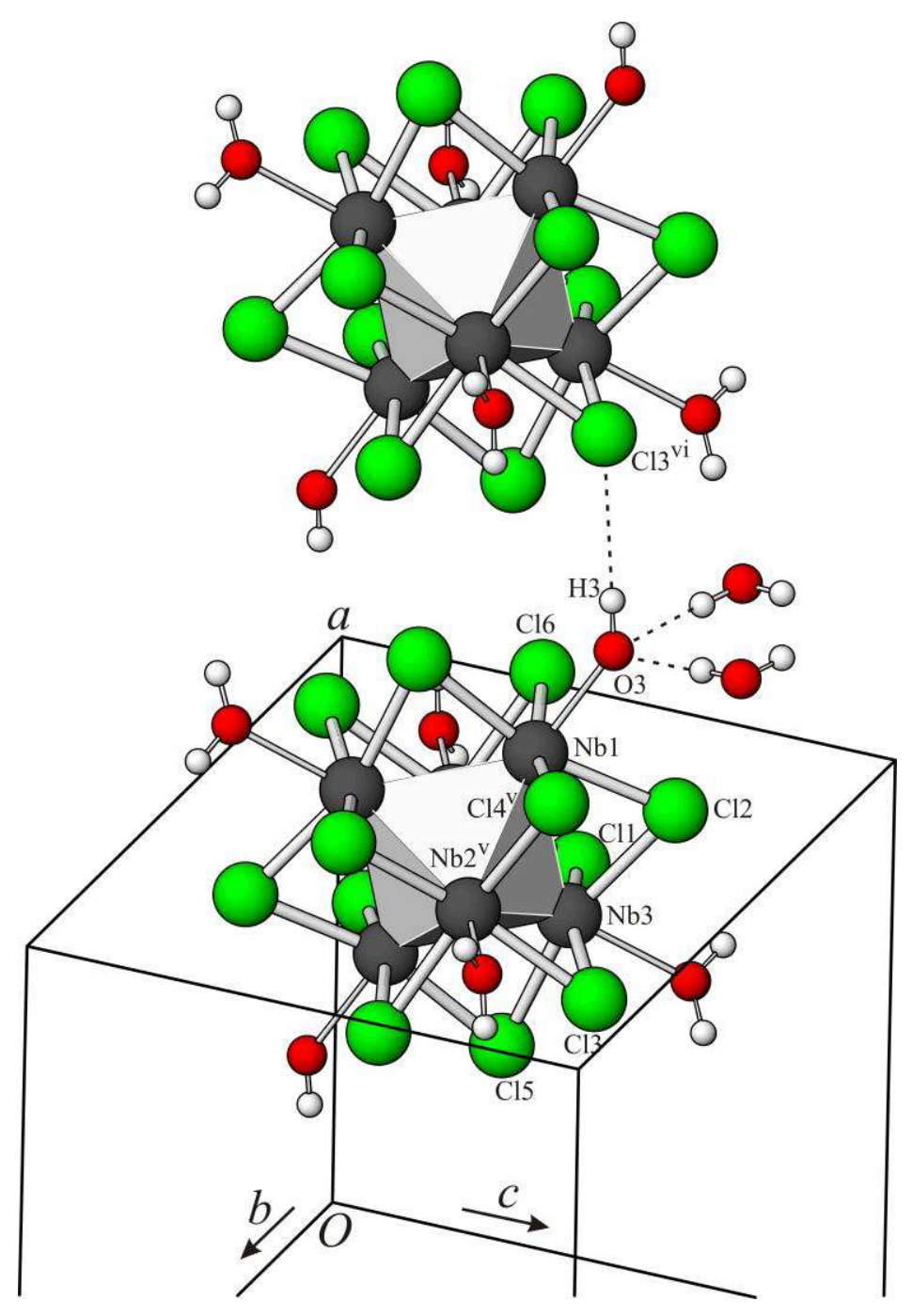

Fig. 2. Structure of $\left[\mathrm{Nb}_{6} \mathrm{Cl}_{12}(\mathrm{OH})_{2}\left(\mathrm{H}_{2} \mathrm{O}\right)_{4}\right] \cdot 4 \mathrm{H}_{2} \mathrm{O}$ (2) optimized in the space group $P \overline{1}$. Positions of all hydrogen atoms are taken according to the scheme proposed in Table 6 of ref. [17], with

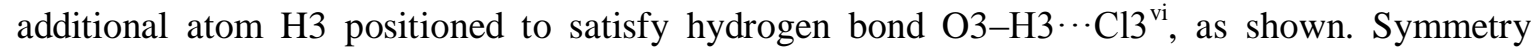
codes: (v) $2-x, 1-y, 1-z$; (vi) $1+x, y, z$ 


\section{Results of PAW and GIPAW calculations}

Calculated eigenvalues of the CS tensors: $\left(\delta_{11}, \delta_{22}\right.$ and $\left.\delta_{33}\right)$, quadrupolar interaction parameters $\left(C_{\mathrm{Q}}\right.$ and $\left.\eta_{\mathrm{Q}}\right)$ and Euler angles $(\alpha, \beta$ and $\gamma)$ for the nuclei which were treated experimentally by the solid-state NMR or NQR spectroscopy in this work are listed in Table 1. Calculated eigenvalues of $\boldsymbol{\sigma}^{\mathrm{sym}}$ tensors: $\left(\sigma_{11}, \sigma_{22}\right.$ and $\left.\sigma_{33}\right), C_{\mathrm{Q}}$ and $\eta_{\mathrm{Q}}$ parameters and Euler for all other sites (nuclei) in the structures of $\mathbf{1}$ and $\mathbf{2}$ are deposited in supplementary material (Table S3). Precision of calculated parameters is estimated according to the small differences between values obtained for symmetrically related sites during the PAW(GIPAW) calculation of $\mathbf{1}$. Such differences were not observed during calculation for $\mathbf{2}$, due to only one class of symmetry operations in the space group of $2(P \overline{1})$. Euler angles were calculated within precision of one degree. The CS tensors for $\mathrm{Nb}$ sites in both compounds and for $\mathrm{Cl}$ sites in 2 were calculated by using Eq. (1) with values $\sigma_{\text {ref }}=-578.09 \mathrm{ppm}$ for ${ }^{93} \mathrm{Nb}$ [5], and $\sigma_{\text {ref }}=974$ ppm for ${ }^{35} \mathrm{Cl}$ [4]. Due to the lack of information for $\sigma_{\text {ref }}$ values of ${ }^{79} \mathrm{Br}$ or ${ }^{81} \mathrm{Br}$ nuclei, the eigenvalues of symmetric part of shielding tensor $\left(\sigma^{\mathrm{sym}}\right)$ are given for Br1 site in $\mathbf{1}$ (Table 1 ). This nucleus was treated only by NQR spectroscopy; therefore experimental $\delta_{11}, \delta_{22}$ and $\delta_{33}$ values for this site are not determined. Graphical ellipsoid representations of calculated EFG and $\boldsymbol{\sigma}^{\text {sym }}$ tensors, for all symmetrically inequivalent $\mathrm{Nb}, \mathrm{Br}$ and $\mathrm{Cl}$ sites forming the cluster units in $\mathbf{1}$ and $\mathbf{2}$ are given in Fig. 3. For sake of clarity, principal axes of $\boldsymbol{\sigma}^{\text {sym }}$ ellipsoids for specific atomic types have been normalized to the average values of their isotropic values $\left\langle\sigma_{i s o}(\mathrm{Nb})\right\rangle,\left\langle\sigma_{i s o}(\mathrm{Br})\right\rangle$ and $\left\langle\sigma_{i s o}(\mathrm{Cl})\right\rangle$. Therefore, $\sigma^{\mathrm{sym}}$ ellipsoids of different atom types in Fig. 3 are not comparable in size mutually. (In reality, $\sigma^{\text {sym }}$ tensors on $\mathrm{Nb}$ sites are much larger than $\sigma^{\text {sym }}$ tensors on $\mathrm{Cl}$ or $\mathrm{Br}$ sites, but ellipsoids among atoms of the same type are mutually comparable.) The EFG ellipsoids were not normalized, so their sizes are comparable even between atoms of different types. It is interesting that $\mathrm{Nb}$ sites show deshielding effect, i.e. the local magnetic fields felt by their nuclei are higher than the fields used in experiment. For all other atoms, principal values of shielding are positive (Table S3 in supplementary material), meaning that magnetic fields felt by their nuclei are lowered by the induced molecular currents, as typical for the concept of chemical shift. In less symmetrical compound $\mathbf{2}$, there are no symmetry restrictions on individual tensor components or on Euler angles, due to the general crystallographic positions for every atom. In higher symmetric compound $\mathbf{1}$, EFG parameters for the $\mathrm{Hg}$ atom are zero due to its high, tetrahedral, symmetry site [8b Wyckoff position of the $F d \overline{3}$ space group (origin choice 2)]. Furthermore, the calculated $\sigma^{\text {sym }}$ tensor for this atom is isotropic (Table S3 in supplementary material). Atom $\mathrm{Br} 2$, positioned on the three-fold inversion axis has perfect axial symmetry of the EFG and $\boldsymbol{\sigma}^{\mathrm{sym}}$ tensors (equal values for $\sigma_{11}$ and $\sigma_{22}$ and zero value for $\eta_{\mathrm{Q}}$, as evident from Table S3 in supplementary material). Niobium atoms and oxygen atoms from coordinated water molecules lie on the crystallographic two-fold axis [48f Wyckoff positions in the space group $F d \overline{3}$ (origin choice 2)], so one of principal axes of their EFG and $\sigma^{\text {sym }}$ (CS) tensors must be aligned along this symmetry axis. According to the PAW/GIPAW calculations for Nb1 site these are the $V_{z z}$ and $\sigma_{33}$ principal axes, so $\beta$ Euler angle for this site is zero. Two-fold crystallographic axis is close to the approximate four-fold molecular symmetry of the whole $\left[\mathrm{Nb}_{6} \mathrm{Br}_{12}\right]^{2+}$ cluster core (only hydrogen atoms from coordinated water molecules destroy this symmetry) and this is reflected in the small computed $\eta_{\mathrm{Q}}$ value. The same arguments can explain small $\beta$ Euler 
angles and small $\eta_{\mathrm{Q}}$ values for all three niobium sites in $\mathbf{2}$ ( $\mathrm{Nb} 1, \mathrm{Nb} 2$ and $\mathrm{Nb} 3$ ), although all these sites have no crystallographic symmetry. Contrary to $\mathrm{Nb}$ sites, the PAW/GIPAW calculations predict that bridging halogen sites (Br1 in 1 and Cl1-Cl6 in 2) have high anisotropic EFG and $\sigma^{\text {sym }}$ (CS) tensors [especially EFG tensors, as evident from Figs. 3(a) and 3(c)]. So, they have high $\eta_{\mathrm{Q}}$ values (Table 1). Principal axes $V_{x x}$ lie dominantly in the plane of $\mathrm{Nb}-\mathrm{X}$ bonds $\left(\mathrm{X}=\right.$ halogen atom), $V_{y y}$ principal axes point radial, outwards the cluster unit and $V_{z z}$ principal axes are oriented perpendicular to the plane of $\mathrm{Nb}-\mathrm{X}$ bonds [Figs. 3(a) and 3(c)]. Directions of the smallest shielding (largest shift) on bridging halogen sites $\left(\sigma_{11}\right)$ are oriented radial, outwards the cluster units. Orientations of other principal $\sigma^{\text {sym }}$ tensor axes are less regular compared to the orientations of principal axes of the EFG tensor.
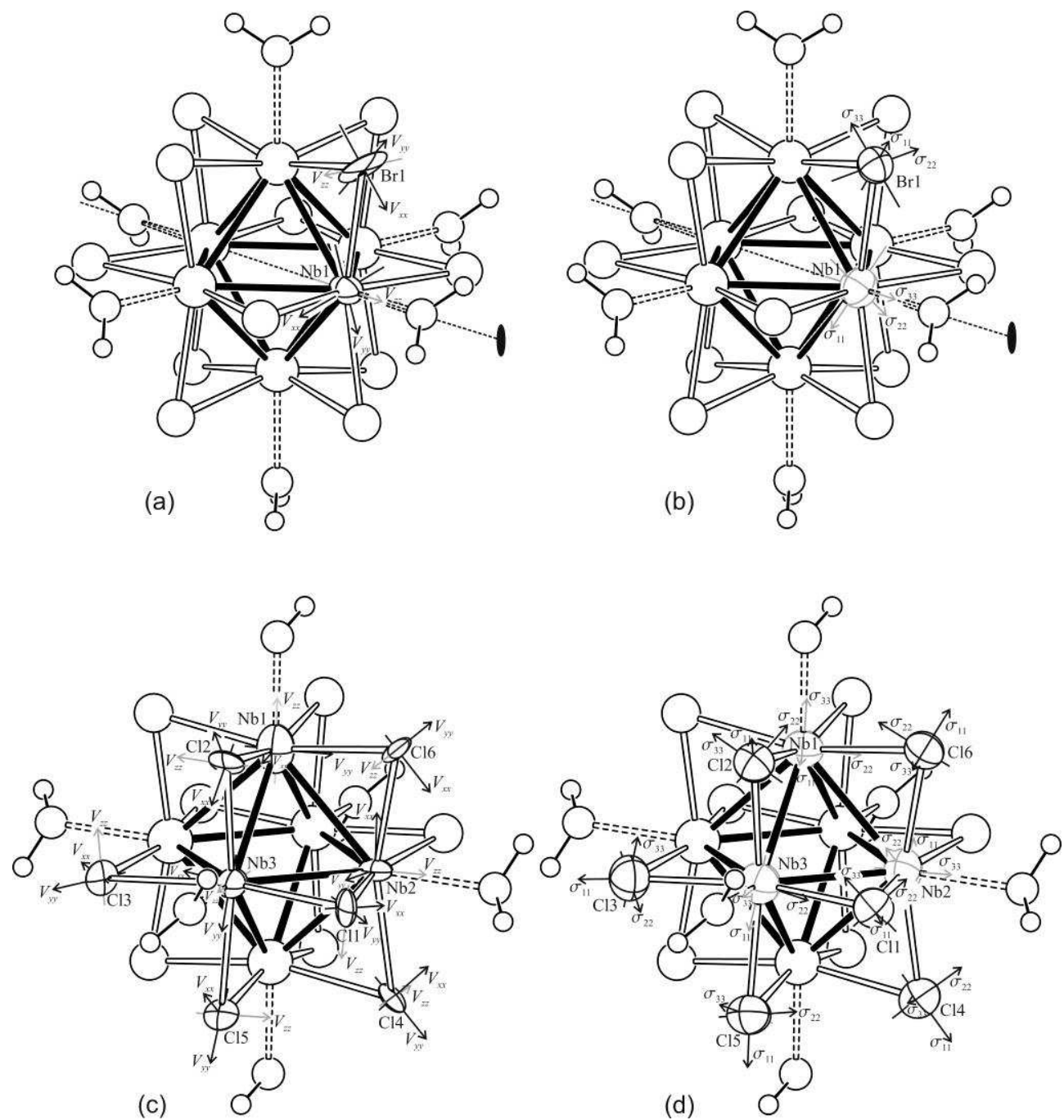

Fig. 3. Ellipsoid representation of the calculated EFG tensors in $\mathbf{1}$ and $\mathbf{2}$ [(a) and (c)] and $\boldsymbol{\sigma}^{\mathrm{sym}}$ tensors in $\mathbf{1}$ and $\mathbf{2}$ [(b) and (d)]. Ellipsoids are drawn only on the symmetry inequivalent $\mathrm{Nb}, \mathrm{Br}$ or $\mathrm{Cl}$ sites of clusters in $\mathbf{1}$ and $\mathbf{2}$; other symmetry related sites are represented by circles. Individual principal axes of EFG or $\sigma^{\mathrm{sym}}$ tensors are labelled with $V_{x x}, V_{y y} V_{z z}$ or $\sigma_{11}, \sigma_{22} \sigma_{33}$, respectively, denoting those with negative eigenvalues in gray. In (a) and (b), two-fold rotation axis of $F d \overline{3}$ space group is denoted as a thick dashed line. 
Table 1. GIPAW calculated and experimentally determined CS and EFG parameters for $\mathrm{Nb}, \mathrm{Br}$ and $\mathrm{Cl}$ sites of cluster units in $\left[\mathrm{Nb}_{6} \mathrm{Br}_{12}\left(\mathrm{H}_{2} \mathrm{O}\right)_{6}\right]\left[\mathrm{HgBr}_{4}\right] \cdot 12 \mathrm{H}_{2} \mathrm{O}(\mathbf{1})$ and $\left[\mathrm{Nb}_{6} \mathrm{Cl}_{12}(\mathrm{OH})_{2}\left(\mathrm{H}_{2} \mathrm{O}\right)_{4}\right] \cdot 4 \mathrm{H}_{2} \mathrm{O}(\mathbf{2})$

\begin{tabular}{|c|c|c|c|c|c|c|c|c|c|}
\hline \multicolumn{10}{|c|}{$\left[\mathrm{Nb}_{6} \mathrm{Br}_{12}\left(\mathrm{H}_{2} \mathrm{O}\right)_{6}\right]\left[\mathrm{HgBr}_{4}\right] \cdot 12 \mathrm{H}_{2} \mathrm{O}$} \\
\hline Nucleus & $\delta_{11}\left(\sigma_{11}\right)(\mathrm{ppm})$ & $\delta_{22}\left(\sigma_{22}\right)(\mathrm{ppm})$ & $\delta_{33}\left(\sigma_{33}\right)(\mathrm{ppm})$ & $C_{\mathrm{Q}}(\mathrm{MHz})$ & $\eta_{Q}$ & $\alpha\left(^{0}\right)$ & $\beta\left(\left(^{0}\right)\right.$ & $\gamma\left({ }^{0}\right)$ & Method \\
\hline${ }^{93} \mathrm{Nb} 1$ & 2652 & 2553 & 1955 & 81.90 & 0.020 & 0 & 0 & 28 & GIPAW \\
\hline${ }^{93} \mathrm{Nb} 1$ & $3400(50)$ & $3300(50)$ & $2300(50)$ & 83.76 & 0 & 0 & 0 & 0 & ssNMR(NQR) \\
\hline${ }^{81} \mathrm{Br} 1$ & $1251^{\mathrm{a}}$ & $1321^{\mathrm{a}}$ & $1476^{a}$ & 124.89 & 0.958 & 0 & 89 & 76 & GIPAW \\
\hline \multicolumn{10}{|c|}{$\left[\mathrm{Nb}_{6} \mathrm{Cl}_{12}(\mathrm{OH})_{2}\left(\mathrm{H}_{2} \mathrm{O}\right)_{4}\right] \cdot 4 \mathrm{H}_{2} \mathrm{O}$} \\
\hline Nucleus & $\delta_{11}(\mathrm{ppm})$ & $\delta_{22}(\mathrm{ppm})$ & $\delta_{33}(\mathrm{ppm})$ & $C_{\mathrm{Q}}(\mathrm{MHz})$ & $\eta_{\mathrm{Q}}$ & $\alpha\left(^{0}\right)$ & $\beta\left(^{0}\right)$ & $\gamma\left({ }^{0}\right)$ & Method \\
\hline${ }^{93} \mathrm{Nb} 1$ & 2737 & 2657 & 2188 & 116.49 & 0.116 & 75 & 3 & 115 & GIPAW \\
\hline${ }^{93} \mathrm{Nb} 1$ & $2690(50)$ & $2610(50)$ & $2050(50)$ & 140.09 & 0.056 & 0 & 0 & 0 & ssNMR(NQR) \\
\hline${ }^{93} \mathrm{Nb} 2$ & 3039 & 2886 & 2203 & 56.06 & 0.235 & 75 & 3 & 72 & GIPAW \\
\hline${ }^{93} \mathrm{Nb} 2$ & $3200(100)$ & $3100(100)$ & $2100(100)$ & 75.25 & 0.118 & 0 & 0 & $90(30)$ & ssNMR(NQR) \\
\hline${ }^{93} \mathrm{Nb3}$ & 2859 & 2833 & 2148 & 77.05 & 0.020 & 87 & 6 & 177 & GIPAW \\
\hline${ }^{93} \mathrm{Nb3}$ & $3100(100)$ & $3100(100)$ & 1900(100) & $83.00(81.70)^{b}$ & 0 & 0 & 0 & 0 & ssNMR(NQR) \\
\hline${ }^{35} \mathrm{Cl1}$ & 721 & 604 & 560 & 17.18 & 0.606 & 13 & 46 & 92 & GIPAW \\
\hline${ }^{35} \mathrm{Cl} 2$ & 674 & 604 & 573 & 16.00 & 0.727 & 33 & 27 & 61 & GIPAW \\
\hline${ }^{35} \mathrm{Cl} 3$ & 597 & 494 & 475 & 15.53 & 0.777 & 14 & 22 & 66 & GIPAW \\
\hline${ }^{35} \mathrm{Cl} 4$ & 629 & 538 & 519 & 15.45 & 0.791 & 3 & 14 & 83 & GIPAW \\
\hline${ }^{35} \mathrm{Cl} 5$ & 618 & 512 & 500 & 15.60 & 0.623 & 15 & 87 & 84 & GIPAW \\
\hline${ }^{35} \mathrm{Cl} 6$ & 686 & 581 & 545 & 15.91 & 0.650 & 31 & 11 & 75 & GIPAW \\
\hline
\end{tabular}

${ }^{a}$ Eigenvalues of symmetric magnetic shielding $\left(\sigma_{11}, \sigma_{22}, \sigma_{33}\right)$ are given.

${ }^{\mathrm{b}}$ Value in parentheses is from the independent NQR measurement. 


\section{NMR and NQR measurements}

\section{1. $\left[\mathrm{Nb}_{6} \mathrm{Br}_{12}\left(\mathrm{H}_{2} \mathrm{O}\right)_{6}\right]\left[\mathrm{HgBr}_{4}\right] \cdot 12 \mathrm{H}_{2} \mathrm{O}(\mathbf{1})$}

Simulated ${ }^{93} \mathrm{Nb}$ solid-state NMR spectra at $B=6.0034 \mathrm{~T}$ and $B=12.0142 \mathrm{~T}$, using parameters from the PAW/GIPAW calculation, (Table 1; compound 1, Nb1 site, GIPAW method), are shown in Figs. 4(a) and 4(b), respectively. Measured spectra in the same fields are shown in Figs. 4(e) and 4(f), respectively. Lineshapes of simulated spectra nicely follows those obtained experimentally, although simulations show shift towards the lower $\delta$ values. This is especially visible on the $12.0142 \mathrm{~T}$ spectra [Fig. 4(b)]. Left and right shoulders of characteristic central transition line are predicted to be below 4000 and slightly above $0 \mathrm{ppm}$, respectively, but experiment show that they occur around 4500 and 500 ppm [Fig. 4(f)]. To test the quality of quadrupolar interaction parameters that can significantly affect the appearance of the spectra, additional determination of $C_{\mathrm{Q}}$ and $\eta_{\mathrm{Q}}$ parameters is performed by zero field NQR spectroscopy. The results are given in Figs. 5(a) and 5(b). From positions of two lines, identified as $\pm 5 / 2 \leftrightarrow \pm 7 / 2$ and $\pm 7 / 2 \leftrightarrow \pm 9 / 2{ }^{93} \mathrm{Nb}$ transitions, one can easily extract the EFG parameters: $C_{\mathrm{Q}}=83.76 \mathrm{MHz}$ and $\eta_{\mathrm{Q}}=0$ [Eqs. (7) - (10)].
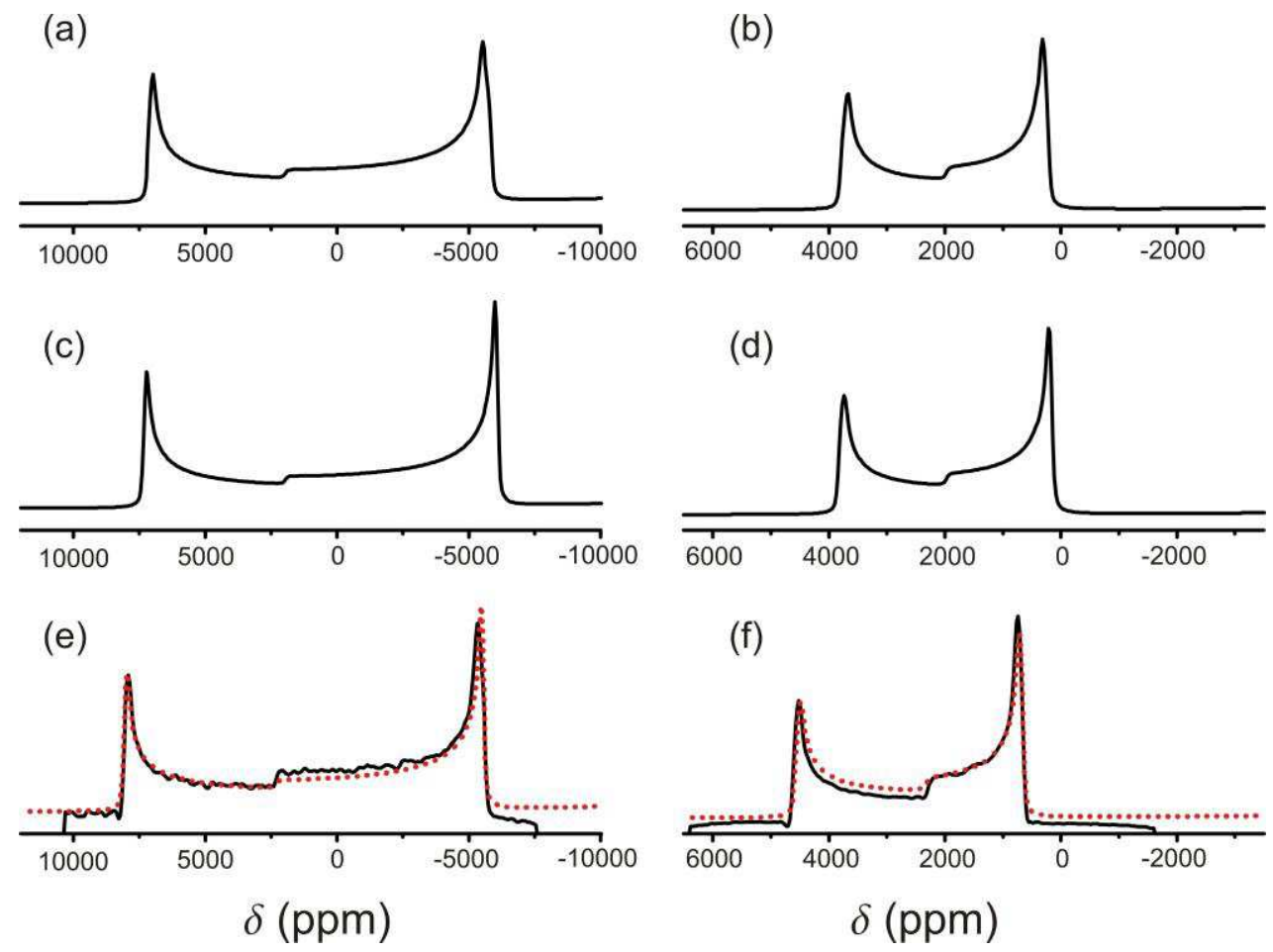

Fig. 4. Solid-state NMR powder-spectra of central transition of ${ }^{93} \mathrm{Nb}$ nuclei in $\left[\mathrm{Nb}_{6} \mathrm{Br}_{12}\left(\mathrm{H}_{2} \mathrm{O}\right)_{6}\right]$ $\left[\mathrm{HgBr}_{4}\right] \cdot 12 \mathrm{H}_{2} \mathrm{O}(\mathbf{1})$ : simulations at $6.0034 \mathrm{~T}$ (a) and $12.0142 \mathrm{~T}$ (b) with parameters obtained from the PAW/GIPAW calculations. Simulations at $6.0034 \mathrm{~T}$ (c) and $12.0142 \mathrm{~T}$ (d) with $\delta_{11}, \delta_{22}, \delta_{33}, \alpha$, $\beta$ and $\gamma$ parameters obtained from the GIPAW calculation and EFG parameters obtained from the NQR measurements. Measured spectra (black line) at $6.0034 \mathrm{~T}$ (e) and $12.0142 \mathrm{~T}$ (f), with simulations using NMR parameters obtained by the best fit to both measured spectra (dotted line). 
Simulated NMR spectra using these values for $C_{\mathrm{Q}}$ and $\eta_{\mathrm{Q}}$, together with values for $\delta_{11}, \delta_{22}$, $\delta_{33}, \alpha, \beta$ and $\gamma$ obtained from the GIPAW calculation are given in Figs. 4(c) and 4(d). This simulation even better reproduces overall width and shape of experimental spectra [Figs. 4(e) and 4(f)], although still shifted for $\sim 500 \mathrm{ppm}$ towards the lower $\delta$ values. Simulations based only on the PAW/GIPAW predictions [Figs. 4(a) and 4(b)] produce somewhat narrower spectrum in comparison with the measured ones, due to slightly lower prediction for $C_{\mathrm{Q}}$ parameter (81.90 MHz, compared with 83.76 MHz obtained from the NQR). Nevertheless, the difference is only $1.861 \mathrm{MHz}(2.2 \%)$, which shows high reliability of the PAW method for calculation of EFG tensor in this case. Thereafter, the $\mathrm{NQR}$ determined $C_{\mathrm{Q}}$ and $\eta_{\mathrm{Q}}$ parameters were fixed and other parameters were varied in order to produce the best simulation of both measured spectra simultaneously [Figs. 4(e) and 4(f)]. By using this fitting procedure, the experimentally determined CS parameters are obtained which are given in Table 1 (ssNMR/NQR method). To do so, each parameter $\left(\delta_{11}, \delta_{22}, \delta_{33}, \alpha, \beta\right.$ and $\left.\gamma\right)$ was varied bidirectionally, with all others being kept constant, until the shape variation was significant. Simulations showed that the shape of spectra was insensitive to variations of Euler angles $\alpha, \beta$ and $\gamma$. Structural/symmetry reasons could be responsible for this observation: Euler angle $\beta$ for $\mathrm{Nb} 1$ site is zero by symmetry reasons, as already explained in the previous section. The NQR measurements show that the $\eta_{\mathrm{Q}}$ asymmetry parameter is also zero, meaning that EFG tensor is axially symmetric. In such axial case, the $V_{x x}$ and $V_{y y}$ principal axes of the EFG tensor can always be chosen in direction of $\delta_{11}$ and $\delta_{22}$ principal axes of the CS tensor (even if CS is not axially symmetric), therefore the other two Euler angles $(\alpha$, and $\gamma)$ can always be redefined to zero, regardless of the initial orientation of $V_{x x}$ and $\delta_{11}$ principal axes. Thus, the simulations of ${ }^{93} \mathrm{Nb}$ solid-state NMR spectra for this site should not be sensitive to the variation of Euler angles.
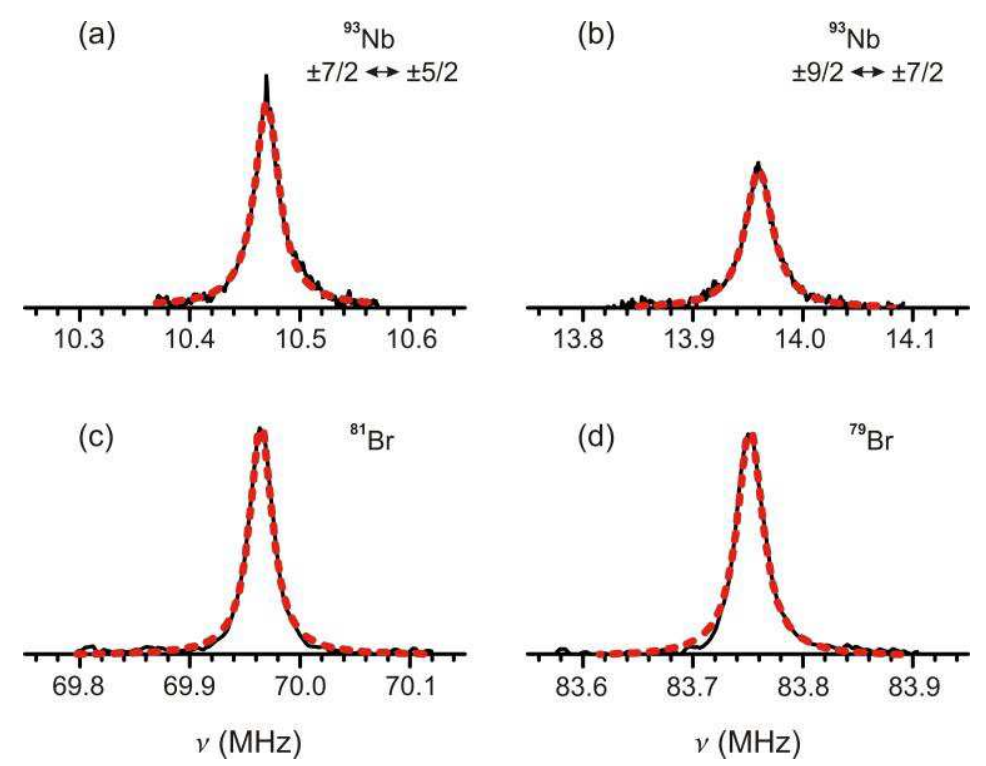

Fig. 5. NQR spectra of $\left[\mathrm{Nb}_{6} \mathrm{Br}_{12}\left(\mathrm{H}_{2} \mathrm{O}\right)_{6}\right]\left[\mathrm{HgBr}_{4}\right] \cdot 12 \mathrm{H}_{2} \mathrm{O}$, together with their Lorentzian fits (dashed lines): ${ }^{93} \mathrm{Nb}$ transition $\pm 7 / 2 \leftrightarrow \pm 5 / 2$ (a): $v_{0}=10.46997 \mathrm{MHz}, \Delta v_{0}=26.69 \mathrm{kHz} ;{ }^{93} \mathrm{Nb}$ transition $\pm 9 / 2 \leftrightarrow \pm 7 / 2$ (b): $v_{0}=13.96004 \mathrm{MHz}, \Delta v_{0}=30.26 \mathrm{kHz}$; transitions $\pm 3 / 2 \leftrightarrow \pm 1 / 2$ of ${ }^{81} \mathrm{Br}(\mathrm{c})$ and ${ }^{79} \mathrm{Br}(\mathrm{d})$, respectively $\left({ }^{81} v_{\mathrm{Q}}=69.96464 \mathrm{MHz}, \Delta{ }^{81} v_{\mathrm{Q}}=24.27 \mathrm{kHz} ;{ }^{79} v_{\mathrm{Q}}=\right.$ 83.75187 MHz, $\left.\Delta^{79} v_{\mathrm{Q}}=28.04 \mathrm{kHz}\right)$. 
Zero value of NQR measured $\eta_{\mathrm{Q}}$ parameter compared to small PAW prediction could be a consequence of the coordinated water molecule dynamics. Namely, torsion movements of these molecules around $\mathrm{Nb}-\mathrm{O}$ bonds could increase crystallographic two-fold symmetry existing in $F d \overline{3}$ structural model into higher four-fold symmetry, for which axial appearance of the tensors is obligatory. The NMR/NQR measurements are performed on temperatures of $200 \mathrm{~K}$, while the PAW/GIPAW calculations are performed on the optimized geometry, where atomic movements or rotations around bonds are not taken into account.

According to all these arguments and after determination of $C_{\mathrm{Q}}$ and $\eta_{\mathrm{Q}}$ by $\mathrm{NQR}$, the parameters that should affect the shape of simulated ${ }^{93} \mathrm{Nb}$ solid-state NMR spectra of $\mathbf{1}$ are only $\delta_{11}, \delta_{22}$ and $\delta_{33}$ parameters. The best fits are obtained by using values of 3400(50), $3300(50)$ and 2300(50) ppm for $\delta_{11}, \delta_{22}$ and $\delta_{33}$, respectively [Table 1; compound $\mathbf{1}, \mathrm{Nb} 1$ site, $\operatorname{ssNMR}(\mathrm{NQR})$ method]. In Haeberlen notation [Eqs. (4) - (6)] these parameters are $\delta_{\text {iso }}=$ $3000(50) \mathrm{ppm}, \delta_{\text {aniso }}=-1050(50) \mathrm{ppm}$ and $\eta_{\delta}=0.1429$. GIPAW calculation underestimates the $\delta_{11}, \delta_{22}$ and $\delta_{33}$ parameters between $200-800 \mathrm{ppm}(8-24 \%)$, although correctly predict a positive sign for all three eigenvalues. Simulations of spectra were rather insensitive to the variation of $\delta_{11}, \delta_{22}$ and $\delta_{33}$ parameters, so their accuracy is estimated to $50 \mathrm{ppm}$.

Regarding ${ }^{81 / 79} \mathrm{Br}$ NQR measurements, measured frequencies of ${ }^{81} v_{\mathrm{Q}}=69.97 \mathrm{MHz}$ and ${ }^{79} v_{\mathrm{Q}}=83.75 \mathrm{MHz}$ [Figs. 5(c) and 5(d)] correspond very well with the PAW predicted values ${ }^{81} v_{\mathrm{Q}}=71.43 \mathrm{MHz}$ and ${ }^{79} v_{\mathrm{Q}}=85.5 \mathrm{MHz}$, respectively, showing again that EFG parameters in compound 1 are calculated with high precision. The solid-state NMR measurements on ${ }^{81 / 79} \mathrm{Br}$ nuclei were not performed, due to their lower receptivity and high ratios of their quadrupolar to Larmor frequencies. Characteristic quadrupolar frequencies calculated from the PAW predicted $C_{\mathrm{Q}}$ and $\eta_{\mathrm{Q}}$ values are $35.68 \mathrm{MHz}$ for ${ }^{81} \mathrm{Br}$ and $42.71 \mathrm{MHz}$ for ${ }^{79} \mathrm{Br}$ [Eq. (1.2) from ref. [7]]. In order to extract the CS parameters for $\mathrm{Br} 1$ site in compound $\mathbf{1}$, it is desirable to perform ${ }^{81 / 79} \mathrm{Br}$ solid-state NMR measurements on the high-field solid-state NMR facilities where quadrupolar interaction is better treated by second-order perturbation theory, and where effects from chemical shift anisotropy are enlarged.

\section{2. $\left.\mathrm{Nb}_{6} \mathrm{Cl}_{12}(\mathrm{OH})_{2}\left(\mathrm{H}_{2} \mathrm{O}\right)_{4}\right] \cdot 4 \mathrm{H}_{2} \mathrm{O}(2)$}

Simulated ${ }^{93} \mathrm{Nb}$ solid-state NMR spectra at 6.1952, 9.0977 and $12.0003 \mathrm{~T}$, using PAW/GIPAW calculated parameters (Table 1; compound 2, Nb1, Nb2 and Nb3 sites, GIPAW method) are shown in Figs. 6(a) - (c), respectively. Measured spectra in the same fields are shown in Figs. 6(g) - (i), respectively. The overall shape of the simulated spectra (based on sum of the three individual sites) is in poorer agreement with the measured spectra, compared with the analogous analysis in the case of compound $\mathbf{1}$. In order to determine more reliable $C_{\mathrm{Q}}$ and $\eta_{\mathrm{Q}}$ parameters, the additional zero field NQR measurements were recorded between 8.8 and $24 \mathrm{MHz}$. The results are shown in Fig. 7. There are seven detected resonant frequencies: Three lines correspond to $\mathrm{Nb} 1$ site, two correspond to $\mathrm{Nb} 2$ site and two correspond to $\mathrm{Nb} 3$ site. Remaining five lines were below experimentally accessible range (i.e. below $8.8 \mathrm{MHz}$ ). Nevertheless, one can easily determine $C_{\mathrm{Q}}$ and $\eta_{\mathrm{Q}}$ parameters for all these three sites by using Eqs. (7) - (10). Results are given in Table 1 [compound 2; ssNMR(NQR) method, for Nb3 site $C_{\mathrm{Q}}$ value determined from $\mathrm{NQR}$ is the one given in parentheses]. It can be observed that the PAW predictions underestimate these NQR determined values up to $26 \%$ (the largest 
relative discrepancy is for the $\mathrm{Nb} 2$ site). Nevertheless, the PAW calculation correctly predicts the largest $C_{\mathrm{Q}}$ parameter on $\mathrm{Nb1}$ site, which is special site because it bonds negative charged hydroxyl anion instead of neutral water molecule. At ellipsoid presentation of EFG tensors of cluster sites in 2 [Fig. 3(c)], it is visible that the largest EFG ellipsoid is drawn on the Nb1 site. PAW underestimations of $\eta_{\mathrm{Q}}$ values on all $\mathrm{Nb}$ sites can be argued by dynamical effects of bonded water (or hydroxyl) molecules. When $C_{\mathrm{Q}}$ and $\eta_{\mathrm{Q}}$ parameters measured by NQR spectroscopy are combined with values for $\delta_{11}, \delta_{22}, \delta_{33}, \alpha, \beta$ and $\gamma$ obtained from the GIPAW calculation, significant improvement in matching between simulated [Figs. 6(d) - 6(f)] and the observed [Figs. 6(g) - 6(i)] ${ }^{93} \mathrm{Nb}$ solid-state NMR spectra is achieved. Using the same fitting procedure as used in the analysis of compound 1, experimental values for $\delta_{11}, \delta_{22}, \delta_{33}, \alpha, \beta$ and $\gamma$ are obtained [Table 1; Nb1, Nb2 and Nb3 sites, ssNMR(NQR) method]. In order to produce the best fit it was necessary to slightly change $C_{\mathrm{Q}}$ parameter of the $\mathrm{Nb3}$ site (with respect to the NQR measured value), although we consider that this small difference is in the range of experimental uncertainties. Again, simulations showed that the shape of solid-state NMR spectra was insensitive to variation of Euler angles, although $90^{\circ}$ for the $\gamma$ angle on Nb2 site was found to be the most suitable. This site has the largest $\eta_{\mathrm{Q}}$ value,
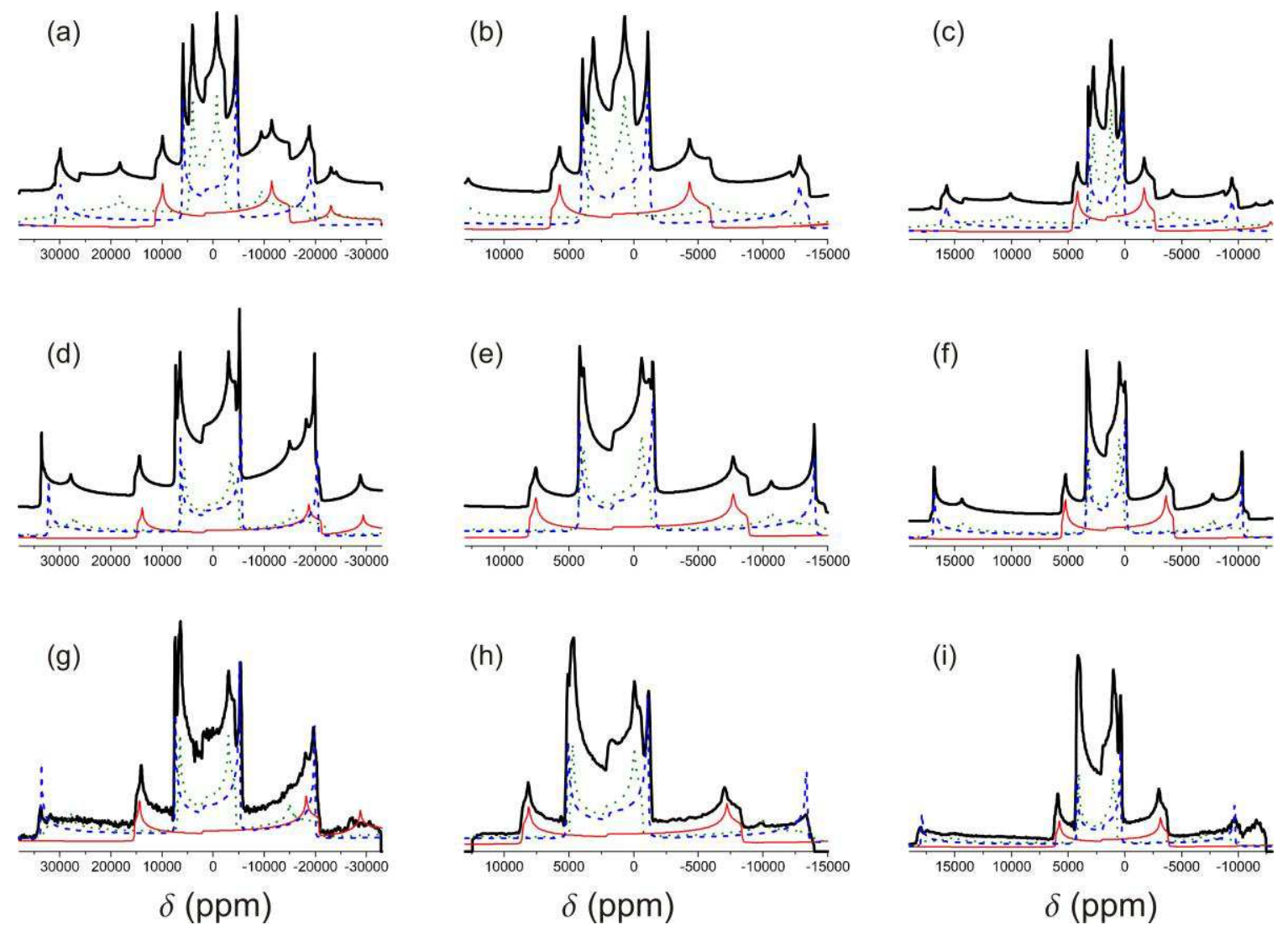

Fig. 6. Solid-state NMR powder-spectra of the central transition of ${ }^{93} \mathrm{Nb}$ nuclei in $\left[\mathrm{Nb}_{6} \mathrm{Cl}_{12}(\mathrm{OH})_{2}\left(\mathrm{H}_{2} \mathrm{O}\right)_{4}\right] \cdot 4 \mathrm{H}_{2} \mathrm{O}$ : Simulations at $6.1952 \mathrm{~T}$ (a), $9.0977 \mathrm{~T}$ (b) and $12.0003 \mathrm{~T}$ (c) using parameters obtained by the PAW/GIPAW calculation; simulations at $6.1952 \mathrm{~T}$ (e), $9.0977 \mathrm{~T}$ (f) and $12.0003 \mathrm{~T}$ (g) using $\delta_{11}, \delta_{22}, \delta_{33}, \alpha, \beta$ and $\gamma$ parameters from the GIPAW calculation and EFG parameters from the NQR measurements; measured spectra at $6.1952 \mathrm{~T}(\mathrm{~g}), 9.0977 \mathrm{~T}(\mathrm{~h})$ and $12.0003 \mathrm{~T}$ (i). In all spectra contributions from individual $\mathrm{Nb}$ sites are shown; Nb1-thin full line, $\mathrm{Nb} 2$ - dashed line and $\mathrm{Nb} 3$ - dotted line. 
so the arguments given in analysis of compound $\mathbf{1}$ (redefinition of Euler angles to zero) are not strictly valid for this site. Due to overlapping of lineshapes from the three inequivalent $\mathrm{Nb}$ sites on all three measured spectra [Figs. 6(g) - (i)], the precision of experimentally determined $\delta_{11}, \delta_{22}$ and $\delta_{33}$ parameters was lower than the analogous precision of these parameters obtained during analysis of compound $\mathbf{1}$, especially for the $\mathrm{Nb} 2$ and $\mathrm{Nb} 3$ sites. Nevertheless, the best fitted $\delta_{11}, \delta_{22}$ and $\delta_{33}$ values very well agree with those predicted by the GIPAW calculation, even better than analogous correspondence in the case of compound $\mathbf{1}$. All predicted values for $\delta_{11}, \delta_{22}$ and $\delta_{33}$ parameters, from all three sites, do not differ for more than $270 \mathrm{ppm}(9 \%)$ from the experimentally determined values (Table 1). Additionally, in Figs. 6(g) - 6(i) one can also observe a few signals from the additional satellite transitions, and these were also included during the simulation-fitting procedure.

It is difficult to explain differences in PAW predicted and NMR/NQR measured values for the $C_{\mathrm{Q}}$ and $\eta_{\mathrm{Q}}$ parameters at niobium sites of 2 , but we can suspect in correct description of hydrogen bonding network. We relied on the scheme suggested by the singlecrystal X-ray diffraction study [17], although it is known that the light hydrogen atoms have small scattering power and cannot be reliably determined by X-rays, especially if they compose the structure containing heavy atoms like niobium. Due to the large number of symmetry independent hydrogen atoms in the structure of 2 ( 9 atoms, Table S1 of supplementary material), the other hydrogen bonding schemes are also possible, which could produce a different $C_{\mathrm{Q}}$ and $\eta_{\mathrm{Q}}$ parameters. Determination of most suitable hydrogen bonding scheme is out of the scope of this paper. Anyway, the proper assignation of $\mathrm{Nb}$ sites in experimental ${ }^{93} \mathrm{Nb}$ solid-state NMR spectra is achieved. To obtain correct assignation, the usage of additional NQR measurements proved to be very useful, because they correct the values for quadrupolar interaction parameters.

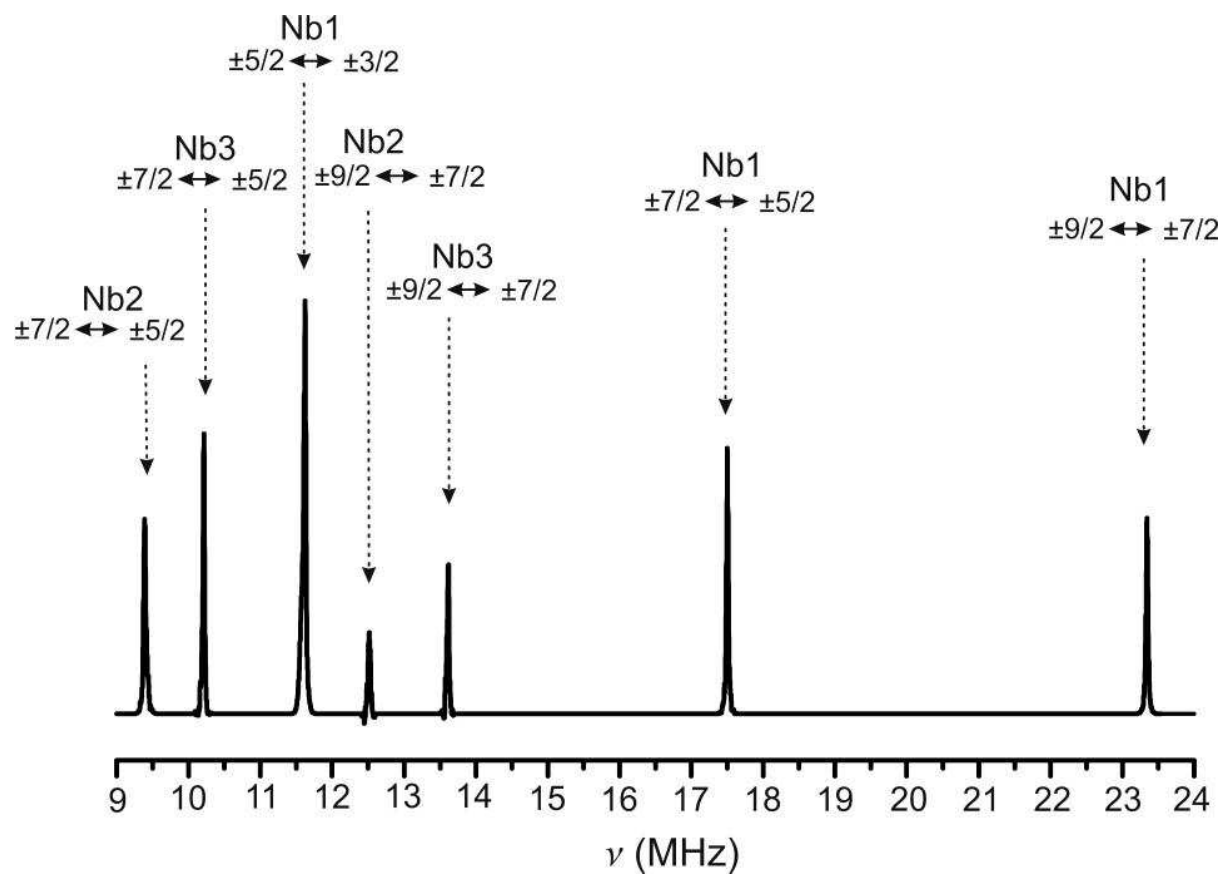

Fig. 7. $\mathrm{NQR}$ spectra of, $\left[\mathrm{Nb}_{6} \mathrm{Cl}_{12}(\mathrm{OH})_{2}\left(\mathrm{H}_{2} \mathrm{O}\right)_{4}\right] \cdot 4 \mathrm{H}_{2} \mathrm{O}$ : Each of three niobium sites contributes to four NQR lines. 7 (out of 12) lines are observed in the available frequency range. 
In order to deeply describe the halogen bridging $\mathrm{Cl}$ sites in compound $\mathbf{2}$, the powder ${ }^{35} \mathrm{Cl}$ solid-state NMR spectra in $B=12.0135 \mathrm{~T}$ was recorded and it is shown in Fig. 8(b). Due to the large number of symmetry inequivalent $\mathrm{Cl}$ sites (6 sites), we were not able to experimentally determine all NMR parameters for each site by using simulation-fitting procedure. Nevertheless, the general shape of simulation spectra reproduces the measured one more than satisfactory (Fig. 8). From this we can conclude that the PAW/GIPAW calculation reliably predicts the NMR parameters characteristic for these sites of halogen atoms. We point out a good correspondence for predicted and observed lineshape discontinuities, as this feature was not so successful in the case of ${ }^{93} \mathrm{Nb}$ spectra of compound 1 (there, the shift towards the lower $\delta$ values was observed).

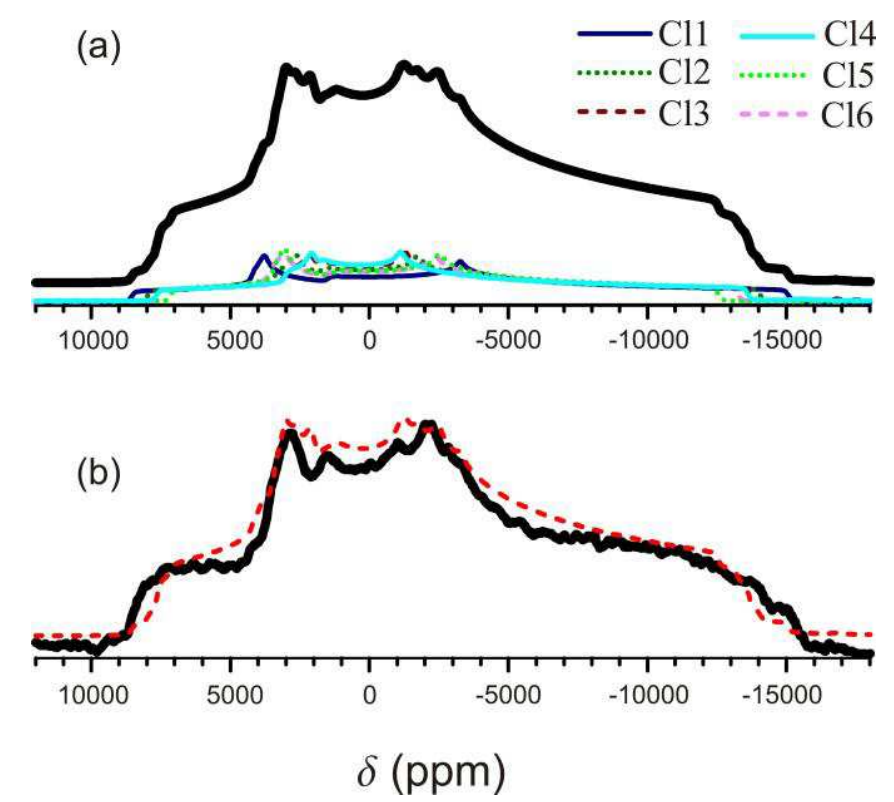

Fig. 8. (a) Simulated ${ }^{35} \mathrm{Cl}$ powder NMR spectra of $\left[\mathrm{Nb}_{6} \mathrm{Cl}_{12}(\mathrm{OH})_{2}\left(\mathrm{H}_{2} \mathrm{O}\right)_{4}\right] \cdot 4 \mathrm{H}_{2} \mathrm{O}$ using the PAW/GIPAW calculated parameters (black thick line), showing contributions for each of individual $\mathrm{Cl}$ sites.; (b) Measured ${ }^{35} \mathrm{Cl}$ powder NMR spectra (black thick line) compared with theoretical prediction (dashed line).

\section{6. ${ }^{93} \mathrm{Nb}$ chemical shifts}

The most striking feature of the ${ }^{93} \mathrm{Nb}$ chemical shifts in hexanuclear halide cluster units is that they show deshielding effects. According to presented analysis, which is based on independent PAW/GIPAW calculation and solid-state NMR measurements, the values for chemical shifts are positive, contrary to the all recently reviewed niobate systems [4]. Positive shifts on niobium sites are rare, but they can be found in few compounds, for example in bidendate ligand complexes of $\mathrm{NbX}_{5}(\mathrm{X}=\mathrm{Cl}, \mathrm{Br})\left[\left\{\mathrm{o}-\mathrm{C}_{6} \mathrm{H}_{4}\left(\mathrm{CH}_{2} \mathrm{YMe}_{2}\right)_{2}\right\},\left\{\mathrm{MeY}\left(\mathrm{CH}_{2}\right)_{2} \mathrm{YMe}\right\}\right.$ or $\left.\left\{{ }^{\mathrm{n}} \mathrm{BuSe}\left(\mathrm{CH}_{2}\right)_{2} \mathrm{Se}{ }^{\mathrm{n}} \mathrm{Bu}\right\} \quad(\mathrm{Y}=\mathrm{S}, \mathrm{Se})\right]$, although with values much smaller than those determined/calculated in this work [36]. We notice that here reported values are similar to those observed for ${ }^{95} \mathrm{Mo}$ shifts in hexanuclear molybdenum bromide cluster compounds $\left[\mathrm{Bu}_{4} \mathrm{~N}\right]\left[\mathrm{Mo}_{6} \mathrm{Br}_{14}\right], \mathrm{Cs}_{2} \mathrm{Mo}_{6} \mathrm{Br}_{14}$ and $\mathrm{MoBr}_{2}$, where each cluster unit contain diamagnetic $\left[\mathrm{Mo}_{6} \mathrm{Br}_{8}\right]^{4+}$ cluster core [18]. Indeed, both forms of clusters, edge-bridged niobium and facecapped molybdenum are similar, they both are classified as hexanuclear clusters with $\pi$-donor 
ligands [37] and their electronic structure is explained by the same molecular-orbital scheme [37]. A difference is that $\mathrm{Nb}_{6}$ metal core uses $d_{x y}$ metal orbitals for metal-metal bonding, leaving $d_{x^{2}-y^{2}}$ to metal-halogen bonding, while Mo 6 metal core uses $d_{x^{2}-y^{2}}$ for metal-metal bonding and $d_{x y}$ for metal-halogen bonding [37]. Fragments around metal atom defined by the nearest non-metal atoms in both clusters also have similar features; they are square-pyramid fragments. In mentioned molybdenum clusters from ref. [18] the pyramidal apex is occupied by $\mathrm{Br}^{-}$anions, while in niobium clusters from this work, the pyramidal apex is occupied by water molecules or by hydroxyl anions. Finally, in both types of clusters formal metal oxidation state is low, in molybdenum cluster it is +2 , while in niobium it is $+2 \frac{1}{3}$. These oxidation states are formal because oxidation has to be attributed to whole cluster units and not to individual metal atoms. Thus, properties of electron systems around niobium or molybdenum atoms in these clusters should be similar and according to the results of this study and the results of study in ref. [18], they produce strong deshielding effects.

Regarding comparison between calculated shifts (shieldings) with experimental results, we observed that niobium bromide compound 1 fails up to 26\%. The choice of the reference may be at the origin of this discrepancy: We used a value of $-578.09 \mathrm{ppm}$ for $\sigma_{\text {ref }}\left({ }^{93} \mathrm{Nb}\right)$, the value that is determined by the theoretical/experimental work on large system of niobate compounds [4]. Niobium atoms in all these systems show negative chemical shifts and thus, the value of $-578.09 \mathrm{ppm}$ could not be representative for a set of hexanuclear niobium halide cluster compounds. As we analysed only two compounds (4 different niobium sites as a whole) we consider that this is not enough large set of data to extract $\sigma_{\text {ref }}\left({ }^{93} \mathrm{Nb}\right)$ by linear regression in analysis of correlation between calculated isotropic shieldings and measured isotropic shifts, according to the methods described in refs. [12] and [18]. Thus, we have to include more hexanuclear niobium cluster structures in future research of NMR properties of nuclei in these clusters, probably using high-field facilities and techniques described in ref. [2], to increase precision of measured $\delta_{11}, \delta_{22}$ and $\delta_{33}$ parameters.

\section{Conclusion}

In this work we presented that all sites of hexanuclear niobium halide cluster (metal and halogen sites) are amenable to the analysis with solid-state NMR technique enriched with the PAW/GIPAW calculations. By using these methods we obtained a sensitive probe into structural/electronic properties of these cluster compounds. Chemical shifts on niobium are large and positive (2400-3000 ppm), comparable to recently analysed chemical shifts of related molybdenum cluster compounds [18]. Quadrupolar interaction parameters can be calculated to high precision if the structure has high symmetry and unambiguous hydrogen bonding scheme. Regularities between tensor properties of NMR parameters and structural features of cluster units have been observed, for example the largest principal axis of the EFG tensor $\left(V_{z z}\right)$ is perpendicular to the $\mathrm{X}-\mathrm{Nb}$ bonds, intermediate principal axis of the EFG tensor $\left(V_{y y}\right)$ and the largest principal axis of the CS tensor $\left(\delta_{11}\right)$ are oriented in the radial direction with respect to the centre of the $\left[\mathrm{Nb}_{6} \mathrm{X}_{12}\right]^{2+}$ unit.

This work is an additional demonstration of the power of the computational approach using PAW and GIPAW methods in order to go further in the analysis of the NMR spectra. 
Although computations of NMR parameters of heavy nuclei such as ${ }^{79 / 81} \mathrm{Br}$ of ${ }^{93} \mathrm{Nb}$ is less obvious than the one of lighter elements from a theoretical point of view (relativistic effects, pseudo-potentials), our results show an overall excellent agreement between experimental and computed NMR parameters. This is all the more impressive since hexanuclear niobium clusters are complex chemical systems where chemical bonding is strongly delocalized over metallic atoms and capping ligands [37, 38].

\section{Acknowledgments}

This work was supported by Ministry of Science, Education and Sports of the Republic of Croatia (grants no. 098-0982904-2946 and 119-1191458-1022). We acknowledge the grant from the European Commission FP7 project SOLeNeMaR (\#229390). The researches were granted access to the HPC resources of CINES under the allocation 2011-[86170] made by GENCI (Grand Equipement National de Calcul Intensif) 


\section{References}

[1] C. M. Widdifield, A. D. Bain, D. L Bryce, Definitive solid-state ${ }^{186 / 187}$ Re NMR spectral evidence for and analysis of the origin of high-order quadrupole-induced effects for $I=5 / 2$, Phys. Chem. Chem. Phys. 13 (2011) 12413-12420.

[2] O. B. Lapina, D. F. Khabibulin, A. A. Shubin, V. V. Terskikh, Practical aspects of ${ }^{51}$ V and ${ }^{93} \mathrm{Nb}$ solid-state NMR spectroscopy and applications to oxide materials, Prog. Nucl. Mag. Res. Spetrosc. 53 (2008) 128-191.

[3] R. P. Chapman, C. M. Widdifield, D. L. Bryce, Solid-state NMR of quadrupolar halogen nuclei, Prog. Nucl. Mag. Res. Spetrosc. 55 (2009) 215-237.

[4] E. Papulovskiy, A. A. Shubin, V. V. Terskikh, C. J. Pickard, O. B. Lapina, Theoretical and experimental insights into applicability of solid-state ${ }^{93} \mathrm{Nb}$ NMR in catalysis, Phys. Chem. Chem. Phys. 15 (2013) 5115-5131.

[5] J. V. Hanna, K. J. Pike, T. Charpentier, T. F. Kemp, M. E. Smith, B. E. G. Lucier, R. W. Shurko, L. S. Cahill, A ${ }^{93} \mathrm{Nb}$ Solid-State NMR and Density Functional Theory Study of Four- and Six- Coordinate Niobate Systems, Chem. Eur. J. 16 (2010) 32223239 .

[6] C. M. Widdifield, D. L Bryce, A multinuclear solid-state magnetic resonance and GIPAW DFT study of anhydrous calcium chloride and its hydrates, Can. J. Chem. 89 (2011) 754-763.

[7] C. M. Widdifield, D. L. Bryce, Solid-State ${ }^{79 / 81}$ Br NMR and Gauge-Including Projector-Augmented Wave Study of Structure, Symmetry and Hydration State in Alkaline Earth Metal Bromides, J. Phys. Chem. A 114 (2010) 2102-2116.

[8] R. E. McCarley, B. G. Hughes, F. A. Cotton, R. Zimmerman, The Two-Electron Oxidation of Metal Atom Cluster Species of the Type $\left[\mathrm{M}_{6} \mathrm{X}_{12}\right]^{2+}$, Inorg. Chem. 4 (1965) 1491-1492.

[9] S. Nagashima, S. Kamiguchi, K. Kudo, T. Sasaki, T. Chihara, Intramolecular Condensation of 1,2- $\mathrm{C}_{6} \mathrm{H}_{4}\left(\mathrm{CH}_{2} \mathrm{RH}\right)_{2}(\mathrm{R}=\mathrm{O}, \mathrm{S}$, and $\mathrm{NH})$ to Yield Heterocyclic Compounds over Halide-cluster Catalysts, Chem. Lett. 40 (2011) 78-81.

[10] R. K. Harris, E. D. Becker, S. M. Cabral de Menezes, R. Goodfellow, P. Granger, NMR nomenclature, Nuclear spin properties and conventions for chemical shifts (IUPAC Recommendations 2001), Pure Appl. Chem. 73 (2001), 1795-1818.

[11] C. J. Pickard, F. Mauri, All-electron magnetic response with pseudopotentials: NMR chemical shifts, Phys. Rev. B 63 (2001) 245101.

[12] T. Charpentier, The PAW/GIPAW approach for computing NMR parameters: A new dimension added to NMR study of solids, Solid State Nucl. Magn. Reson. 40 (2011) 120. 
[13] C. Bonhomme, C. Gervais, F. Babonneau, C. Coelho, F. Poupiont, T. Azaïs, S. E. Ashbrook, J. M. Griffin, J. R. Yates, F. Mauri, C. J. Pickard, First-Principles Calculation of NMR Parameters Using the Gauge Including Projector Augmented Wave Method: A Chemist's Point of View, Chem. Rev. 112 (2012) 5733-5779.

[14] J. Cuny, J. R. Yates, R. Gautier, E. Furet, E. Le Fur, L. Le Pollès, Electric field gradient calculations in paramagnetic compounds using the PAW approach. Application to ${ }^{23} \mathrm{Na}$ NMR in layered vanadium phosphates, Magn. Reson. Chem. 48 (2010), S171-S175.

[15] J. R. Yates, Prediction of NMR J-coupling in solids with the planewave pseudopotential approach, Magn. Reson. Chem. 48 (2010) S23-S31.

[16] M. Vojnović, S. Antolić, B. Kojić-Prodić, N. Brničević, M. Miljak, I. Aviani, Reactions of Hexanuclear Niobium and Tantalum Halide Clusters with Mercury(II) Halides. Synthesis and structures of the semiconducting compounds $\left[\mathrm{M}_{6} \mathrm{Br}_{12}\left(\mathrm{H}_{2} \mathrm{O}\right)_{6}\right]\left[\mathrm{HgBr}_{4}\right] \cdot 12 \mathrm{H}_{2} \mathrm{O}, \mathrm{M}=\mathrm{Nb}, \mathrm{Ta}, \mathrm{Z}$. Anorg. Allg. Chem. 623 (1997) 12471254.

[17] N. Brničević, P. Planinić, R. E. McCarley, S. Antolić, M. Luić, B. Kojić-Prodić, Synthesis and structural characterization of three new compounds containing $\left[\mathrm{Nb}_{6} \mathrm{Cl}_{12}\right]^{2+}$ units as hydrated hydroxides, J. Chem. Soc., Dalton Trans. (1995) 14411446.

[18] J. Cuny, S. Cordier, C. Perrin, C. J. Pickard, L. Delevoye, J. Trébosc, Z. Gan, L. Le Pollès, R. Gautier, ${ }^{95}$ Mo Solid-State Nuclear Magnetic Resonance Spectroscopy and Quantum Simulations: Synergetic Tools for the Study of Molybdenum Cluster Materials, Inorg. Chem. 52 (2013) 617-627.

[19] D. Massiot, I. Farnan, N. Gautier, D. Trumeau, A. Trokiner, J. P. Coutures, ${ }^{71}$ Ga and ${ }^{69} \mathrm{Ga}$ nuclear magnetic resonance study of $\beta-\mathrm{Ga}_{2} \mathrm{O}_{3}$ : resolution of four- and six- fold coordinated Ga sites in static conditions, Solid State Nucl. Magn. Reson. 4 (1995) 241-248.

[20] G. Bergerhoff, I. D. Brown, Inorganic Crystal Structure Database, in: F.H. Allen, G. Bergerhoff, R. Sievers (Eds.), Crystallographic Databases, International Union of Crystallography, Chester, 1987. pp. 77-95.

[21] S. J. Clark, M. D. Segall, C. J. Pickard, P. J. Hasnip, M. J. Probert, K. Refson, M. C. Payne, First principles methods using CASTEP, Z. Kristallogr. 220 (2005) 567-570.

[22] J. P. Perdew, K. Burke, M. Ernzerhof, Generalized Gradient Approximation Made Simple, Phys. Rev. Lett. 77 (1996) 3865-3868.

[23] P. Pulay, Improved SCF convergence acceleration, J. Comput. Chem. 3 (1982) 556560. 
[24] H. J. Monkhorst, J. D. Pack, Special points for Brillouin zone integrations, Phys. Rev. B. 13 (1976) 5188-5192.

[25] J. R. Yates, C. J. Pickard, F. Mauri, Calculation of NMR chemical shifts for extended systems using ultrasoft pseudopotentials, Phys. Rev. B 76 (2007) 024401.

[26] M. Profeta, F. Mauri, C. J. Pickard, Accurate First Principles Prediction of ${ }^{17}$ O NMR Parameters in $\mathrm{SiO}_{2}$ : Assignment of the Zeolite Ferrierite Spectrum, J. Am. Chem. Soc. 125 (2003) 541-548.

[27] R. K. Harris, E. D. Becker, S. M. Cabral de Menezes, P. Granger, R. E. Hoffman, K. W. Zilm, Further conventions for NMR shielding and chemical shifts (IUPAC Recommendations 2008), Pure Appl. Chem. 80 (2008) 59-84.

[28] J. C. Facelli, Chemical shift tensors, Theory and application to molecular structural problems, Prog. Nucl. Magn. Reson. Spectrosc. 58 (2011) 176-201.

[29] Wsolids NMR Simulation Package, Version 1.20.15, K. Eichele, Universität Tübingen, 2011.

[30] S. Adiga, D. Aebi, D. L. Bryce, EFGShield: A Program for Parsing and Summarizing the Results of Electric Field Gradient and Nuclear Magnetic Shielding Tensor Calculations, Can. J. Chem. 85 (2007) 496-505.

[31] L. J. Farrugia, WinGX and ORTEP for Windows: an update, J. Appl. Crystallogr. 45 (2012) 849-854.

[32] A. Weiss, Crystal Field Effects in Nuclear Quadrupole Resonance, Top. Curr. Chem. 30 (1972) 1-76.

[33] B. Perić, D. Jozić, P. Planinić, N. Brničević, G. Giester Synthesis, crystal structure, spectroscopic and thermal properties of $\left[E t_{4} \mathrm{~N}\right]\left[\mathrm{Ta}_{6} \mathrm{Br}_{12}\left(\mathrm{H}_{2} \mathrm{O}\right)_{6}\right] \mathrm{Br}_{4} \cdot 4 \mathrm{H}_{2} \mathrm{O}$ (Et=ethyl)-A new compound with the paramagnetic $\left[\mathrm{Ta}_{6} \mathrm{Br}_{12}\right]^{3+}$ cluster core, J. Solid State Chem. 182 (2009) 2443-2450.

[34] T. K. Hirsch, A System for Tracking Down Hydrogen Positions in Crystal Structures, Z. Anorg. Allg. Chem. 629 (2003) 666-672.

[35] E. Kroumova, J. M. Perez-Mato, M. I. Aroyo, WYCKSPLIT: a computer program for determination of the relations of Wyckoff positions for group-subgroup pair, J. Appl. Crystallogr. 31 (1998) 646.

[36] M. Jura, W. Levason, R. Ratnani, G. Reid, M. Webster, Six- and eight-coordinate thioand seleno-ether complexes of $\mathrm{NbF}_{5}$ and some comparisons with $\mathrm{NbCl}_{5}$ and $\mathrm{NbBr}_{5}$ adducts, Dalton Trans. 39 (2010) 883-891.

[37] Z. Lin, M.-F. Fan, Metal-Metal Interactions in Transition Metal Clusters with $\pi$-Donor Ligands, Struct. Bond. 87 (1997) 35-80. 
[38] B. Fontaine, S. Cordier, R. Gautier, F. Gulo, J.-F. Halet, B. Perić, C. Perrin, Octahedral niobium cluster-based solid state halides and oxyhalides: effects of the cluster condensation via an oxygen ligand on electronic and magnetic properties, New J. Chem. 35 (2011) 2245-2252. 


\section{Supplementary material}

Table S1. DFT optimized fractional atomic coordinates in the structures of $\mathbf{1}$ and $\mathbf{2}$.

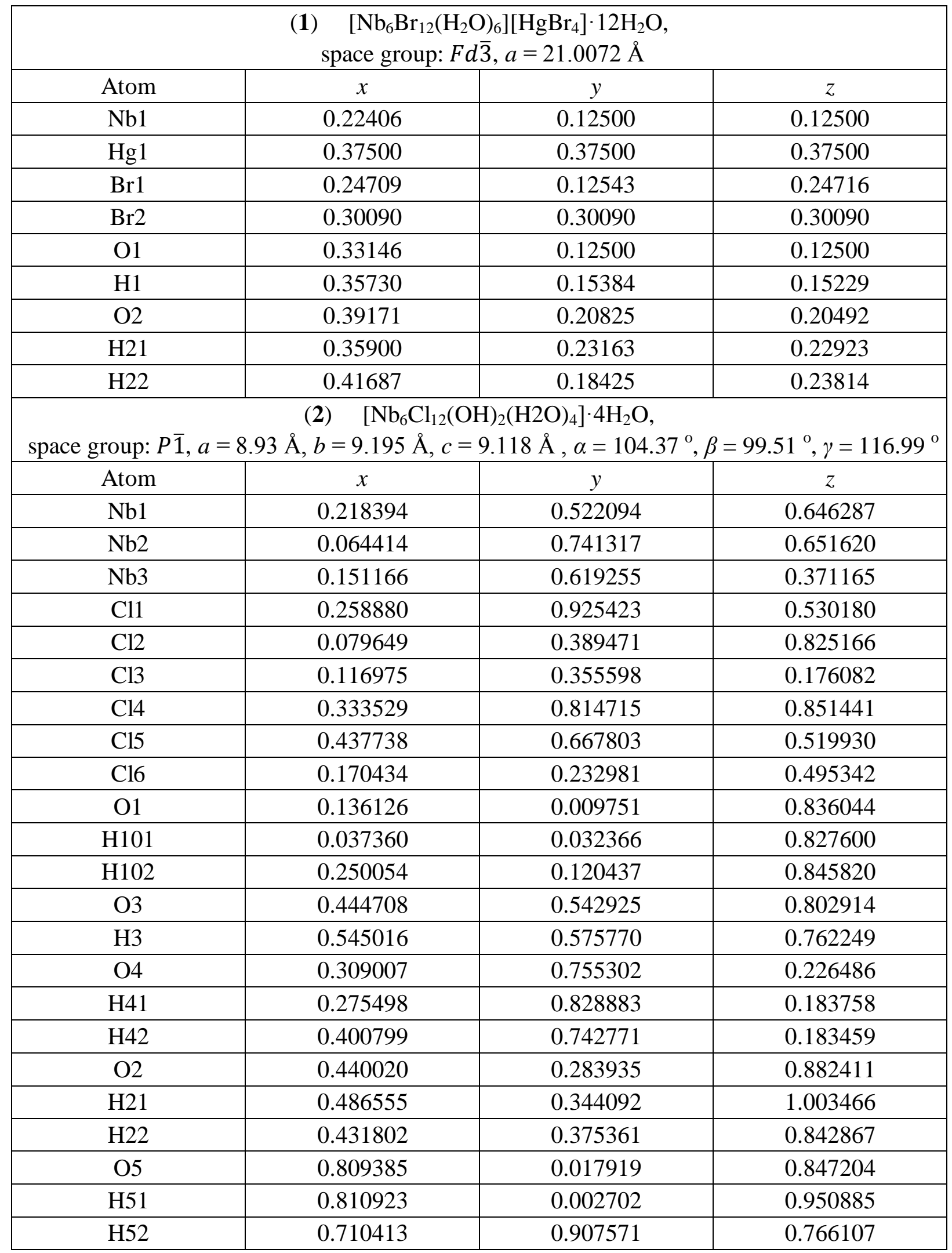


Table S2. Bond distances $(\AA)$ in DFT optimized structures of $\mathbf{1}$ and 2.

\begin{tabular}{|c|c|}
\hline \multicolumn{2}{|c|}{ (1) $\left[\mathrm{Nb}_{6} \mathrm{Br}_{12}\left(\mathrm{H}_{2} \mathrm{O}\right)_{6}\right]\left[\mathrm{HgBr}_{4}\right] \cdot 12 \mathrm{H}_{2} \mathrm{O}$, space group: $F d \overline{3}$} \\
\hline Nb1-Nb1 $1^{\text {vii }}$ & 2.9431 \\
\hline $\mathrm{Nb} 1-\mathrm{Br} 1$ & 2.6114 \\
\hline $\mathrm{Nb} 1-\mathrm{Br} 1^{\mathrm{vii}}$ & 2.6102 \\
\hline $\mathrm{Nb} 1-\mathrm{O} 1$ & 2.2560 \\
\hline O1-H1 & 1.0 \\
\hline $\mathrm{Hg} 1-\mathrm{Br} 2$ & 2.6961 \\
\hline $\mathrm{O} 2-\mathrm{H} 21$ & 0.99 \\
\hline $\mathrm{O} 2-\mathrm{H} 22$ & 1.01 \\
\hline \multicolumn{2}{|c|}{ (2) $\left[\mathrm{Nb}_{6} \mathrm{Cl}_{12}(\mathrm{OH})_{2}(\mathrm{H} 2 \mathrm{O})_{4}\right] \cdot 4 \mathrm{H}_{2} \mathrm{O}$, space group: $P \overline{1}$} \\
\hline $\mathrm{Nb} 1-\mathrm{Nb} 2$ & 2.9061 \\
\hline $\mathrm{Nb} 1-\mathrm{Nb} 3$ & 2.9246 \\
\hline $\mathrm{Nb} 1-\mathrm{Nb} 2^{\text {viii }}$ & 2.9220 \\
\hline $\mathrm{Nb1-Nb3}{ }^{\text {viii }}$ & 2.9045 \\
\hline $\mathrm{Nb} 2-\mathrm{Nb} 3$ & 2.9014 \\
\hline $\mathrm{Nb} 2-\mathrm{Nb} 3^{\text {viii }}$ & 2.9110 \\
\hline $\mathrm{Nb} 1-\mathrm{Cl} 2$ & 2.4425 \\
\hline $\mathrm{Nb} 1-\mathrm{Cl} 4$ & 2.4801 \\
\hline $\mathrm{Nb} 1-\mathrm{Cl} 5$ & 2.4676 \\
\hline $\mathrm{Nb} 1-\mathrm{Cl} 6$ & 2.4699 \\
\hline $\mathrm{Nb} 2-\mathrm{Cl1}$ & 2.4505 \\
\hline $\mathrm{Nb} 2-\mathrm{Cl} 4$ & 2.4538 \\
\hline $\mathrm{Nb} 2-\mathrm{Cl} 3^{\text {viii }}$ & 2.4722 \\
\hline $\mathrm{Nb} 2-\mathrm{Cl6}^{\text {viii }}$ & 2.4348 \\
\hline $\mathrm{Nb} 3-\mathrm{Cl1}$ & 2.4511 \\
\hline $\mathrm{Nb} 3-\mathrm{Cl} 3$ & 2.4785 \\
\hline $\mathrm{Nb} 3-\mathrm{Cl} 5$ & 2.4706 \\
\hline $\mathrm{Nb} 3-\mathrm{Cl} 2^{\text {viii }}$ & 2.4533 \\
\hline $\mathrm{Nb} 1-\mathrm{O} 3$ & 2.1725 \\
\hline $\mathrm{Nb} 2-\mathrm{O} 1^{\mathrm{ix}}$ & 2.3408 \\
\hline $\mathrm{Nb3}-\mathrm{O} 4$ & 2.2638 \\
\hline
\end{tabular}

Symmetry codes: (vii) $z, x, y$; (viii) $-x, 1-y, 1-z$; (xix) $x, 1+y, z$ 
Table S3. Calculated magnetic shielding $\left(\boldsymbol{\sigma}^{\mathrm{sym}}\right)$ and electric field gradient (EFG) parameters

\begin{tabular}{|c|c|c|c|c|c|c|c|c|}
\hline \multicolumn{9}{|c|}{ (1) $\left[\mathrm{Nb}_{6} \mathrm{Br}_{12}\left(\mathrm{H}_{2} \mathrm{O}\right)_{6}\right]\left[\mathrm{HgBr}_{4}\right] \cdot 12 \mathrm{H}_{2} \mathrm{O}$} \\
\hline Nucleus & $\sigma_{11}(\mathrm{ppm})$ & $\sigma_{22}(\mathrm{ppm})$ & $\sigma_{33}(\mathrm{ppm})$ & $C_{\mathrm{Q}}(\mathrm{MHz})$ & $\eta_{\mathrm{Q}}$ & $\alpha\left(^{\mathrm{o}}\right)^{\mathrm{a}}$ & $\beta\left(^{\mathrm{o}}\right)^{\mathrm{a}}$ & $\gamma\left({ }^{0}\right)^{\mathrm{a}}$ \\
\hline${ }^{93} \mathrm{Nb} 1$ & $-3231.5(2)$ & $-3132.5(2)$ & $-2534.72(3)$ & $81.899(2)$ & $0.0197(3)$ & 0 & 0 & 28 \\
\hline${ }^{201} \mathrm{Hg} 1$ & $9436.70(4)$ & $9436.70(4)$ & $9436.70(4)$ & 0 & 0 & 0 & 0 & 0 \\
\hline${ }^{81} \mathrm{Br} 1$ & $1250.72(6)$ & $1321.14(8)$ & $1475.88(9)$ & $-124.8916(8)$ & $0.95802(4)$ & 0 & 89 & 76 \\
\hline${ }^{81} \mathrm{Br} 2$ & $2241.67(7)$ & $2241.67(7)$ & $2778.18(9)$ & $182.508(5)$ & 0 & 0 & 0 & 0 \\
\hline${ }^{17} \mathrm{O} 1$ & $185.773(9)$ & $276.94(1)$ & $410.7(1)$ & $9.239(9)$ & $0.4929(6)$ & 90 & 90 & 90 \\
\hline${ }^{2} \mathrm{H} 1$ & $12.417(4)$ & $12.732(5)$ & $45.578(4)$ & $0.2173(1)$ & $0.1551(1)$ & 4 & 18 & 164 \\
\hline${ }^{17} \mathrm{O} 2$ & $221.92(2)$ & $232.21(3)$ & $254.18(5)$ & $7.074(7)$ & $0.893(1)$ & 84 & 87 & 155 \\
\hline${ }^{2} \mathrm{H} 21$ & $16.221(8)$ & $18.226(9)$ & $44.129(4)$ & $0.25677(5)$ & $0.0894(1)$ & 71 & 5 & 16 \\
\hline${ }^{2} \mathrm{H} 22$ & $8.104(7)$ & $12.738(7)$ & $42.795(4)$ & $0.18659(7)$ & $0.1316(3)$ & 27 & 4 & 64 \\
\hline
\end{tabular}

(2) $\left[\mathrm{Nb}_{6} \mathrm{Cl}_{12}(\mathrm{OH})_{2}(\mathrm{H} 2 \mathrm{O})_{4}\right] \cdot 4 \mathrm{H}_{2} \mathrm{O}$

\begin{tabular}{|c|c|c|c|c|c|c|c|c|}
\hline Nucleus & $\sigma_{11}(\mathrm{ppm})$ & $\sigma_{22}(\mathrm{ppm})$ & $\sigma_{33}(\mathrm{ppm})$ & $C_{\mathrm{Q}}(\mathrm{MHz})$ & $\eta_{\mathrm{Q}}$ & $\alpha\left(^{\mathrm{o}}\right)^{a}$ & $\beta\left(^{\mathrm{o}}\right)^{a}$ & $\gamma\left(^{\mathrm{o}}\right)^{a}$ \\
\hline${ }^{93} \mathrm{Nb} 1$ & -2737.2 & -2657.5 & -2187.6 & 116.492 & 0.116 & 75 & 3 & 115 \\
\hline${ }^{93} \mathrm{Nb} 2$ & -3038.7 & -2885.8 & -2202.8 & 56.060 & 0.2352 & 75 & 3 & 72 \\
\hline${ }^{93} \mathrm{Nb3}$ & -2858.8 & -2833.1 & -2148.2 & 77.051 & 0.0203 & 87 & 6 & 177 \\
\hline${ }^{35} \mathrm{Cl1}$ & 253.44 & 370.97 & 414.33 & 17.1753 & 0.6064 & 13 & 46 & 92 \\
\hline${ }^{35} \mathrm{Cl} 2$ & 300.77 & 371.04 & 401.86 & 16.0024 & 0.7266 & 33 & 27 & 61 \\
\hline${ }^{35} \mathrm{Cl} 3$ & 377.82 & 480.03 & 499.20 & 15.5297 & 0.777 & 14 & 22 & 66 \\
\hline${ }^{35} \mathrm{C} 14$ & 345.37 & 436.04 & 455.67 & 15.4477 & 0.7914 & 3 & 14 & 83 \\
\hline${ }^{35} \mathrm{C} 15$ & 356.48 & 462.99 & 474.47 & 15.6004 & 0.6234 & 15 & 87 & 84 \\
\hline${ }^{35} \mathrm{C} 16$ & 288.78 & 393.56 & 429.09 & 15.9055 & 0.6504 & 31 & 11 & 75 \\
\hline${ }^{17} \mathrm{O} 1$ & 189.78 & 284.14 & 368.98 & 6.9545 & 0.8127 & 75 & 88 & 121 \\
\hline${ }^{2} \mathrm{H} 101$ & 15.255 & 19.585 & 43.528 & 0.2381 & 0.0884 & 0 & 18 & 143 \\
\hline${ }^{2} \mathrm{H} 102$ & 6.738 & 8.580 & 44.391 & 0.1401 & 0.1391 & 0 & 10 & 123 \\
\hline${ }^{17} \mathrm{O} 3$ & 72.662 & 287.33 & 298.37 & -7.0973 & 0.5368 & 3 & 39 & 0 \\
\hline${ }^{2} \mathrm{H} 3$ & 20.988 & 27.802 & 40.960 & 0.2921 & 0.0368 & 0 & 24 & 176 \\
\hline${ }^{17} \mathrm{O} 4$ & 190.732 & 276.278 & 389.020 & 9.5230 & 0.4935 & 88 & 90 & 94 \\
\hline${ }^{2} \mathrm{H} 41$ & 16.083 & 16.646 & 45.497 & 0.2380 & 0.1372 & 4 & 18 & 171 \\
\hline${ }^{2} \mathrm{H} 42$ & 12.254 & 12.892 & 43.742 & 0.1928 & 0.1783 & 6 & 12 & 74 \\
\hline${ }^{17} \mathrm{O} 2$ & 224.390 & 233.727 & 247.083 & 5.6208 & 0.9551 & 69 & 67 & 155 \\
\hline${ }^{2} \mathrm{H} 21$ & 11.494 & 13.732 & 40.454 & 0.1692 & 0.1007 & 44 & 7 & 39 \\
\hline${ }^{2} \mathrm{H} 22$ & 10.381 & 12.346 & 41.666 & 0.1637 & 0.0972 & 48 & 8 & 41 \\
\hline${ }^{17} \mathrm{O} 5$ & 249.212 & 252.075 & 284.810 & 8.3601 & 0.8759 & 90 & 85 & 100 \\
\hline${ }^{2} \mathrm{H} 51$ & 17.285 & 19.675 & 41.264 & 0.2418 & 0.1144 & 81 & 5 & 51 \\
\hline${ }^{2} \mathrm{H} 52$ & 21.582 & 24.086 & 41.267 & 0.2815 & 0.0976 & 2 & 9 & 88 \\
\hline
\end{tabular}

${ }^{a}$ Euler angles are defined as follows: the $\alpha$ angle describe rotation of CS tensor around the $\sigma_{33}$ eigenvector, $\beta$ angle describe rotation of CS tensor about new direction of $\sigma_{22}$ eigenvector and $\gamma$ angle describe rotation of CS tensor about final direction of $\sigma_{33}$ eigenvector. All rotations are counter clockwise, eigenvectors of EFG tensor are not moving and the initial orientation is the one where eigenvectors of $\sigma_{11}, \sigma_{22}$ and $\sigma_{33}$ coincide with eigenvectors of $V_{x x}, V_{y y}$ and $V_{z z}$, respectively. 